\title{
Environmental models in waterfowl management under uncertainty
}

\author{
Dmytro Perepolkin ${ }^{1, *}$
}

\begin{abstract}
The present literature review aims to perform a survey of the decision support models used in waterfowl management. Special attention is dedicated to the origins and practice of adaptive management and modern applications of agent-based models focusing on explicit acknowledgment and treatment of uncertainty in these models.

${ }^{1}$ Centre for Environmental and Climate Research, Lund University

* Correspondence: Dmytro Perepolkin <dmytro.perepolkin@cec.lu.se>
\end{abstract}

\section{Contents}

1 Introduction 2

2 Decision making under risk and uncertainty 3

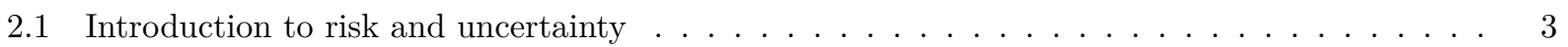

2.2 Brief history of Decision Analysis . . . . . . . . . . . . . . . . . . . 4

3 Decision analysis in environmental management 5

3.1 Decision process approaches . . . . . . . . . . . . . . . . . . 6

3.2 Models in Environmental Management . . . . . . . . . . . . . . . . . . . . 7

3.2.1 Modeling of the system . . . . . . . . . . . . . . . . . . . . 7

3.2 .2 Modeling of decisions . . . . . . . . . . . . . . . . . . . . . . . 9

3.3 Adaptive management under uncertainty . . . . . . . . . . . . . . . . 10

3.4 Passive vs Active Adaptive Management . . . . . . . . . . . . . . . . . . . . . . . . . 12

3.5 Failures of AM as failures of management . . . . . . . . . . . . . . . . . 13

3.6 Adaptive management and VOI . . . . . . . . . . . . . . . . . . . . . 16

4 Waterfowl management under uncertainty 18

4.1 What has been done ... . . . . . . . . . . . . . . . . . . . 18

4.1.1 History of waterfowl management in North America . . . . . . . . . . . . . . . 18

4.1.2 History of waterfown management in Europe . . . . . . . . . . . . . . . . . . 19

4.1.3 Human-nature conflicts and management objectives in waterfowl management . . . . 21

4.1 .4 Management responses and alternatives . . . . . . . . . . . . . . . . . 22

4.2 Models in waterfowl management . . . . . . . . . . . . . . . . . . . . . 23 
4.2.1 Harvest (Population models) . . . . . . . . . . . . . . . . . . . . 23

4.2.2 Habitat (Spatial models for waterfowl movement) . . . . . . . . . . . . . . . 26

4.2 .3 Human dimensions . . . . . . . . . . . . . . . . . . . . . . . . . 28

$\begin{array}{llr}5 & \text { Conclusion } & 30\end{array}$

$\begin{array}{ll}\text { Appendix A } & 31\end{array}$

Markov Decision Process . . . . . . . . . . . . . . . . . . . . . . . . 31

Known and observable process . . . . . . . . . . . . . . . . . . . . . . 31

Uncertain but observable process . . . . . . . . . . . . . . . . . . . . . . . . . . 31

Known but partially observable process . . . . . . . . . . . . . . . . . . . . . 32

Uncertain partially observable process . . . . . . . . . . . . . . . . . . . 33

$\begin{array}{ll}\text { Appendix B } & 34\end{array}$

"Additive" vs "Compensatory" mortality hypotheses . . . . . . . . . . . . . . . . . . 34

\section{Introduction}

Environmental problems are characterized by high complexity, dynamism, stochasticity and interconnectedness of various ecological systems. Management of environmental systems, therefore, entails a great degree of uncertainty. Human interaction with the environment often concerns both exploitation and conservation of ecosystems and, given variety of uses and a large number of actors, involves both human-nature and humanhuman conflicts (Decker and Chase, 1997). All of this necessitates a holistic and systematic approach to decision making related to environmental problems, which addresses both stakeholder alignment (clarity of objectives), uncertainty related to management actions (what can and should be done) and lack-of-knowledge related to how systems will change and respond to these interventions (epistemic and aleatory uncertainty).

Waterfowl management is related to the stewardship of a diverse family of water birds (Order Anseriformes, Family Anatidae) including ducks, swans and geese. This family contains 146 species in 43 genera (magpie goose is now placed into its own family Anseranatidae) (Kear and Hulme, 2005). Many species within the waterfowl family are prized quarry for hunters, because of their large size and good meat quality. Human interest in waterfowl also stirred interest in farming, with many goose and duck species becoming domesticated over 2500 years ago. Swans were bred in capitivity for over 1000 years, as well (Kear and Hulme, 2005). Waterfowl species have historically inhabited wetlands and coastal areas (both fresh water and seaside), but recently human and bird interests have increasingly collided around the use of pastures and agricultural landscapes.

Management of waterfowl pursues objectives related to maintaining these valuable resources for nutritional, recreational and conservation purposes, preserving ecosystems that contribute to thriving populations, while reducing damage induced by abundance of these species onto human interests (residence and farming). These objectives concern many aspects of interaction between humans and waterfowl species. In this paper we adopt classification of waterfowl management areas proposed in Roberts et al. (2018): harvest, habitat, and human dimensions. These areas include annual decisions regarding regulation of waterfowl harvest (hunting), long-term decisions regarding preservation and possible enhancement of habitats, collaborative decisions about protection of agricultural lands and urban areas, including targeted reallocation of crops, scaring practices and recruitment/retention of hunters.

Waterfowl management problems require modeling of animal populations, their interaction with natural landscapes and people. The aim of the paper is to provide an overview of the statistical models and 
methods used for decision making in waterfowl management. The paper surveys the literature on uncertainty analysis and decision analysis in environmental management and focuses on habitat and harvest models for managing the conflict concerning large waterfowl (geese) foraging in agricultural landscapes. Relevant case studies, project work and scientific articles are discussed and international experience in real-world waterfowl management is reviewed and evaluated. The rest of the paper is organized as follows.

In section 2 we introduce the subjects of Decision Analysis and Uncertainty Analysis, giving short introduction into the framework of Structured Decision Making, its scope and origins, as well as various classes of uncertainties which are relevant for environmental decision making.

Section 3 focuses on application of Decision Analysis in environmental management. Various decision frameworks are introduced and relevant models of the system and the decision process itself are discussed. Finally, we introduce Adaptive Management as a framework for making recurring decisions in environmental domain and discuss the role of learning and its trade-off with resource management.

Section 4 explores application of decision analysis under risk and uncertainty to wildlife management, surveying the history of waterfowl management in the USA and in Europe and providing examples of decision models used in the three areas of waterfowl management.

\section{Decision making under risk and uncertainty}

\subsection{Introduction to risk and uncertainty}

According to one of the most renowned definitions proposed by Frank Knight in 1920s (Knight, 1921), "risk" means situations when the outcome is unknown but the probability distribution governing the outcome (also called "frequency distribution" by Morgan et al. (1990)) is well understood, meaning that it is possible to know exactly how likely every outcome is to occur if one were to draw a single sample from this distribution at random. In most cases one needs to have full access to the population of outcomes (at least theoretically, in ad infinitum, as the case is with playing dice) in order to characterize its frequency distribution.

In such situations, it is appropriate to characterize our uncertainty in a randomly picked (sampled) outcome by a probability distribution with the same parameters as the known frequency distribution (Morgan et al., 1990) ${ }^{1}$. Such uncertainty is called "aleatory", from the Latin alea - dice (Fox and Ülkümen, 2011). This type of uncertainty is rarely observed in isolation outside of the gambling halls and board game tables.

In most real life situations, the frequency distribution from which an outcome of interest is drawn ("source distribution"), remains unknown, although domain experts might have sufficient knowledge about the nature of the uncertainty and the likelihood of the outcomes. Often the uncertainty is not merely related to the parameters of a known (or otherwise learnable from data) frequency distribution, but to the fact that the relevant frequency distribution is either unidentified, not yet realized or consists of hypothetical "alternate universe" realizations of the same phenomena. In case the outcome is drawn from the unknown (or undefined) frequency distribution, our indeterminacy about the outcome will consist of two parts: the above mentioned "aleatory" variability due to sampling from a particular frequency distribution and the lack-of-knowledge about such source frequency distribution. This second kind of uncertainty is called epistemic, from the Greek episteme - knowledge - and it is the one most often encountered in the world.

Epistemic uncertainty can also be expressed using probability, but this probability indicates "degree of belief" (O'Hagan, 2004) or "plausibility" (see the basic desiderata in Jaynes, 2003). This probability is "personal", as it rests on the state of knowledge of an agent. However, it is not arbitrary, because it must still be consistent with the probability axioms (Morgan et al., 1990).

When trying to describe unknown a frequency distribution (i.e. when proposing a statistical model to approximate a real-world population or process) it is convenient to think in terms of well-studied parametric

\footnotetext{
${ }^{1}$ This act of personal judgment that the observed relative frequencies are relevant and sufficient for characterizing the probability of obtaining a particular value from a randomly drawn outcome represents the transition from a "frequency" to a "personal probability" domain. Such judgment rests on the assumption of exchangeability (Jaynes, 2003).
} 
distributions, because their parameters acting as numerical characteristics, allow succinct and precise description of fairly complex phenomena (Everitt and Skrondal, 2010). Parametric probability distributions are merely models and, as George E.P. Box famously said, "all models are wrong". However, some models are better than others because they are able to produce better predictions (match the properties of the target frequency distribution better) and therefore they are more "probable" or "plausible" (Morgan et al., 1990).

Epistemic uncertainty can usually be reduced through exploration, experimentation and knowledge acquisition, whereas aleatory uncertainty is assumed to be irreducible (Kleindorfer, 2010). Bayesian Analysis is a framework which allows us to reason (make inferences) about the unknown "parent" frequency distribution based on available samples from it (data). Usually the inference is done about the parameters, while the model (likelihood function) is assumed to be fixed, but the two are closely related, because parameters have meaning only in the context of a particular model, or as Gelman et al. (2017) formulated it, "distribution of parameters (priors) can only be understood in the context of the likelihood".

Morgan et al. (1990) suggest that in many cases model uncertainty can be converted into parameter uncertainty. For example, by introducing a threshold parameter and a dose exponent parameter, a more flexible dose-response model can be built which can accommodate both linear/exponential and threshold/nonthreshold curves. However, in many cases of these "model-switching" categorical parameters, an exhaustive set of alternative models can not be enumerated. Model uncertainty is not only concerned with a choice of probability distribution, but also with the functional form or even an alternative theory (i.e. selection of relevant variables and causal dependencies between them), which is often referred to as structural uncertainty (Bojke et al., 2009). It might be difficult to assign probabilities to such models (since the set is by definition incomplete) and we can only establish their relative plausibility ${ }^{2}$. Cox (2012) proposes a set of methods for dealing with this type of "deep uncertainty", including model averaging, robust optimization and reinforcement learning. Even more extreme case of uncertainty is related to the situation when the system model is not known, which leads to inability to evaluate the system outcomes (Cox, 2012).

While epistemic uncertainty is concerned with a known and bounded imperfection in the current knowledge, ontological uncertainty is related to situations when present knowledge is rendered obsolete by the currently unknown future events, which alter beliefs (models), attitudes (objectives) and behavior (choices) (Derbyshire, 2019). This type of uncertainty is addressed through a set of non-probabilistic scenario tools and methods, which attempt to search for future possibilities without constraints of the present state of knowledge.

\subsection{Brief history of Decision Analysis}

Normative decision theory studies optimal choice among a set of alternatives in light of decision maker's constraints and preferences with the objective of maximizing utility (Arrow, 1957). Traditionally, decision theory has been classified as a special case of optimization within the discipline of Operations Research. Almost all real-life applications, however, deal with some sort of uncertainty, either in the form of variability or limitations in knowledge, or both.

Decision Analysis (DA) as a discipline emerged in 1960s at the interface of statistics, optimization and management science. Its roots can be traced back to the early essays on gambling and game of chance by Gerolamo Cardano (1501-1576). James Bernoulli wrote about probability as "degree of confidence" in 1713. This "personal view" of probability was reiterated by Pierre Simon de Laplace in his Philosophical Essay on Probabilities published in 1812, where he called chance an "expression of man's ignorance", which extended beyond gambling situations to "the most important questions of life". It was only 60 years later, in 1873, that Denis Poisson used the word "probability" as a description of "long-run relative frequency".

In the 20th century, personal view of probability was picked up by John M. Keynes in his A Treatise on Probability published in 1921. Frank Plumpton Ramsey was the first one to formulate a decision-theoretic joint focus on judgmental probability and utility, which expresses itself in the person's willingness to act in the face of risk (i.e. exhibit a behavior resembling betting). This school of thought was further developed by

\footnotetext{
${ }^{2}$ Note that these should never be interpreted as "probability that the model is true"
} 
Bruno de Finetti in 1937, who studied a person's degree of belief by his/her betting behavior. The modern probabilistic theory of utility was formulated by von Neumann and Morgenstern in 1947, which later served as foundation of Savage's "Foundation of Statistics", where he described normative theory of choice under uncertainty (Savage, 1972).

Decision Analysis as a term was first introduced by Ron Howard in 1965 (Matheson, 2005), later adopted and supported by Howard Raiffa in the title of his seminal textbook (Raiffa, 1970). Decision Analysis, as prescriptive school of decision theory, combines statistics, normative decision science, insights from behavioral psychology and organization theory to arrive at a set of recommendations and a description of steps which aim to improve organizational and individual decision making (Brown, 1989). In the environmental management domain these principles were reiterated as Structured Decision Making (Gregory, 2012) which originated from the work of Keeney and Raiffa(Keeney and Raiffa, 1976; Keeney et al., 1999) known as "the East-coast" school of DA. Structured Decision Making proposes a sequence of 5 steps (abbreviated PrOACT):

1) Problem - framing the context of the decision

2) Objectives - identifying objectives and metrics to measure them

3) Alternatives - identifying actions that can help achieve objectives

4) Consequences - characterizing outcomes for each alternative in terms of metrics

5) Trade-offs - illuminating trade-offs between objectives towards clarity of action

The "West-coast" school of DA, primarily based on the contribution of Howard et al. (1977), proposes a similar process known as "six elements of decision quality" (DQ) (Matheson, 2005).

1) Appropriate frame

2) Creative, doable alternatives

3) Meaningful, reliable information

4) Clear values and trade-offs

5) Logically correct reasoning

6) Commitment to action

Decision Analysis is based on the assumption that in a real-life situation very few decision makers are prepared to directly assess probabilities of the outcomes given the alternatives and utilities (the "direct assessment" approach). Instead, "modeling" approach to Decision Analysis requires explicit linking of alternatives and outcomes through structural information gathered from a decision maker or his delegates, creating the "extra-personal representation" of the problem, which can be tested, critiqued, improved and compared to other representations or to itself (Howard, 1980). This approach, in fact, originally described as "decision engineering" (Matheson, 2005) treats decision model as a product, which is developed through stages of pilot, prototype and down to production, when decision is made and implemented. It allows contribution from experts (surfacing disagreement and lack of alignment among them along the way) and serves as a communication and stakeholder management tool for achieving alignment and gaining trust, which help mediate and constructively resolve differences in objectives through de-personalized consideration of tradeoffs.

\section{Decision analysis in environmental management}

The goal of environmental management is to protect human health and well being, as well as to protect (preserve, conserve) other life forms and their habitats (Dupont et al., 1998). Sustainable management of natural resource is based on the understanding that human interaction with nature should be socially, environmentally and economically responsible. Recently these foundational principles have been formulated formulated into 10 tenets of sustainable environmental management (Barnard and Elliott, 2015) requiring environmental management to be: 
- Socially desirable/tolerable

- Ecologically sustainable

- Economically viable

- Technologically feasible

- Legally permissible

- Administratively achievable

- Politically expedient

- Culturally inclusive

- Ethically defensible (morally correct)

- Effectively communicable

The presence and variety of concerns related to sustainable management show that environmental issues are multi-faceted and should be addressed with decision methods that account for multiple objectives and decision criteria conflicts (Keeney and Raiffa, 1976), which can be further exacerbated in the presence of multiple decision makers (Bjerkén, 2020). Many environmental decisions are done in restrictive legal environment and involve multiple government agencies often with conflicting objectives and deal with situation where available management actions may be limited (Grant et al., 2017).

Many environmental decisions are more about people than about nature (Williams, 2018). Top-down implementation of even the most "optimal" policy can affect individuals, raising concern about ethics, participation and possibilities for conflict of interest. Environmental policies implemented on regional scale can be perceived as politicized, not taking into account expertise and tacit knowledge of people affected by them, resulting in lack of buy-in and failures of implementation (Warner et al., 2018).

\subsection{Decision process approaches}

Because environmental decisions deal with complex natural processes and sensitive social issues, they require adoption of sound decision practices and adherence to the process that can help cope with complexity, uncertainty, minimize error (both in understanding of the problem and in making inferences) and ensure stakeholder alignment required for successful decision implementation.

Many approaches to decision making in the environmental domain have been documented in scientific literature:

- Cost-benefit analysis (CBA). This popular method is the most basic approach to decision making: convert both costs and benefits to monetary value and then choose the alternative with the highest expected benefit-to-cost ratio. But as with many methods of economic analysis, there are concerns related to differences in perception of value from consumer and citizen perspectives, high complexity of ecosystems not being reducible to CBA, uniqueness and irreversibility of consequences and challenges with discounting (Hanley, 1992).

- Comparative Risk Assessment (CRA). This method primarily used in policy analysis is aimed at contrasting different policy alternatives across multiple risk dimensions. The end-product in CRA is a decision matrix that provides project alternatives' scores along various criteria (Linkov et al., 2006).

- Alternative Dispute Resolution. The method of decision making based on negotiation and resembling alternative to the courtroom. It usually features a self-designed process that involves "all parties with significant interest" and aims at achieving consensus through dispute resolution and mutual trade-offs. The strife towards consensus effectively grants each stakeholder a veto over the choice of alternatives and a veto over final decision (Gregory et al., 2001).

- Multi-Criteria Decision Analysis (MCDA). A diverse set of methods of systematically eliciting inputs (and structures to represent them), using models for combining these contributions from various stakeholders and experts to rank project alternatives. Huang et al. (2011) performed a review of the environmental management literature surveying the application of three main branches of MCDA: Multi-Attribute Utility Theory (MAUT), Outranking methods (PROMETHEE and ELECTRE) and Analytic Hierarchy Process (AHP) in the previous decade (2000-2009). The study documented growth 
in the number of MCDA-related articles over the period and noted substantial geographical differences in application of various methods, with AHP accounting for almost half of the cases, over $70 \%$ of which were published in Asia and the USA (compare to just 28\% of non-AHP publications appearing out of the same region).

- Adaptive management (AM). Adaptive management is a structured approach to managing natural resources that emphasizes learning through management. It focuses on clarifying goals, designing management actions, specifying causal hypotheses, detailing out procedures for data collection, followed by re-evaluation and repeated iteration of these steps. AM has evolved from the time of its introduction in 1978 (Holling and Programme, 1978; Walters and Hilborn, 1978), but it is still often confused with traditional management through "trial-and-error" (Rist et al., 2013a). Allen et al. (2011) surveys the history of AM and distinguishes two schools of thought within AM: Resilience-Experimentalist (emphasizing stakeholder involvement, resilience and complex models) and Decision-Theoretic school (with stakeholders involved primarily for the purpose of identifying management objectives and employing relatively simple models). The survey distinguishes different degrees of learning in AM. Adaptive Management is concerned with recurring decisions and is often split into the learning phase and analysis phase (Moore et al., 2017). This decision cycle is typically modeled with Markov Decision Process (MDP) and solved with Stochastic Dynamic Programming (Williams, 2009).

- Evidence-based approaches. This approach is based on documenting management interventions and system responses with the aim of building a body of knowledge distillable to "best practice" answers to typical problems. The evidence-based approach was developed within the field of medicine and revolutionized the medical practice (Sutherland et al., 2004). Gillson et al. (2019) discusses application of evidence-based approach in conservation, contrasting it with Adaptive Management and exploring common grounds between the two methodologies. The authors conclude that evidence based conservation (EBC) should indeed be seen as integral part of Adaptive Management cycle for technically complicated problems where it might be easier to reach an agreement among the stakeholders. This combination of EBC and AM would be complimentary and synergistic, building organizational capacity and experience of experts working with accumulation of evidence and implementing policies.

\subsection{Models in Environmental Management}

\subsubsection{Modeling of the system}

Environmental systems are rich in multiple types of uncertainty (Williams et al., 1996), including:

- natural variation: due to the stochastic nature of the environment.

- limited observability: ability to estimate key parameters of the system only to the extent allowed by available monitoring programs.

- limited controllability: limited ability to enforce that the intended interventions are implemented as planned.

- structural uncertainty: an incompleteness of understanding of the underlying ecological processes. It includes parametric and (causal) model uncertainty.

Quantitative models express assumptions and hypotheses about relevant areas of environmental management and provide input into monitoring and directions for further research (Roberts et al., 2018). In particular, decision models encode hypotheses about system response to potential management actions, which can be validated against predictions of multiple alternative mechanistic models to refine scientific understanding of the system (Rehme et al., 2011). In complex systems this response can be non-linear and sometimes counter-intuitive.

Models used for decision support should also capture causal structure of the system under consideration and allow fast propagation of assumption to results, together with relevant uncertainty in parameters. Decision models should be linked to management objectives (allow for performing inferences on any measure of interest), accommodate a wide spectrum of management alternatives (e.g. they shouldn't prevent decision 
makers from generating and testing out new strategies) and yet remain transparent and easy to understand. By highlighting the areas of knowledge with high learning potential, decision models link research and management and help clarify stakeholder values and focus on management objectives (Runge et al., 2011).

Schuwirth et al. (2019) propose six criteria for assessing adequacy of ecological models:

1. There exists a basic process-based understanding of the system regarding causality, which is considered in the model.

2. The model input and output variables are aligned with the management question.

3. The model has an appropriate spatial and temporal resolution to address the management question.

4. The model uncertainty can be quantified.

5. The model has a sufficient predictive performance to be useful for the management problem.

6. The modeling procedure, its assumptions, and its deficits are transparently communicated.

The authors define "theory-based data science" as a combination of data-driven and theory-driven modeling approaches, where mechanistic (process-based) models are combined sequentially with statistical models (Baker et al., 2018). Statistical models can be used for exploratory data analysis and formulating of causal hypotheses which can be tested in subsequent experiments and, if confirmed, contribute to refined understanding of the system, feeding back into original mechanistic models.

Figure 1 captures suitability of various model types depending on understanding of the system and abundance of data. When a system is well understood ordinary differential equations (ODE) or individual/agent based models (IBM/ABM) may be used. Process-based (whether causal or time-referenced) "mechanistic" models are perfectly suited to take into account the individual differences between different sub-classes of species. They are also uniquely positioned to model movement, foraging and social interactions within the animal groups (DeAngelis and Diaz, 2019). Individual Based Models can be used for simulating interaction between nature ecosystem and humans and testing out various management actions.

In data-rich situations, certain machine learning methods may be justified (e.g. Artificial Neural Networks, ANN). Modern machine learning models are targeting prediction based primarily on correlations and associative relationships between variables, disregarding causal structure and mechanistic understanding of the phenomena of interest (Baker et al., 2018).

Perhaps the most popular approach in the literature is utilizing statistical models, such as Generalized Linear Models (GLM) or Generalized Additive Models (GAM), along with more holistic Hierarchical Bayesian Models (HBM), Structural Equation Models (SEM) and other methods based on modeling of latent state variables (Hidden Markov Models, HMM), which explicitly account for the differences between system process and observation process.

For example, in the multi-species duck harvesting decision study described in Johnson et al. (2019) a statespace approach with a discrete logistic model was used for modeling annual population growth (post-harvest). Then based on time series of population size and harvest rate (harvest size), hierarchical Bayesian model was used to estimate model parameters (carrying capacity, population growth rate and process error). The sequential harvesting decisions were then modeled as Markov Decision Process (Williams, 2009) and solved with stochastic dynamic programming (Marescot et al., 2013). An optimal harvesting strategy is defined as the one that maximizes return (harvest size) over an infinite time horizon.

As with any sufficiently complex system, the question often emerges how much detail should be included into the model for it to be useful for decision making, signifying a trade-off between verisimilitude and cogency (Howard, 2007). Schuwirth et al. (2019) argue for a "reductionist" approach, where preference is given to modeling universal, transferable phenomena, which can be implemented (and reused) in mechanistic models with the aim to reduce number of parameters to be estimated. Howard (2007) defends a pragmatic approach wherein only details material to decision should be included, which implies iterative nature of modeling (i.e. identifying important decision drivers, and then modeling them in sufficient detail).

Opponents of using ecological models in environmental decision making cite low levels of familiarity with models, lack of trust in impartiality of modelers, lack of relevant data or quantitative judgments as the 


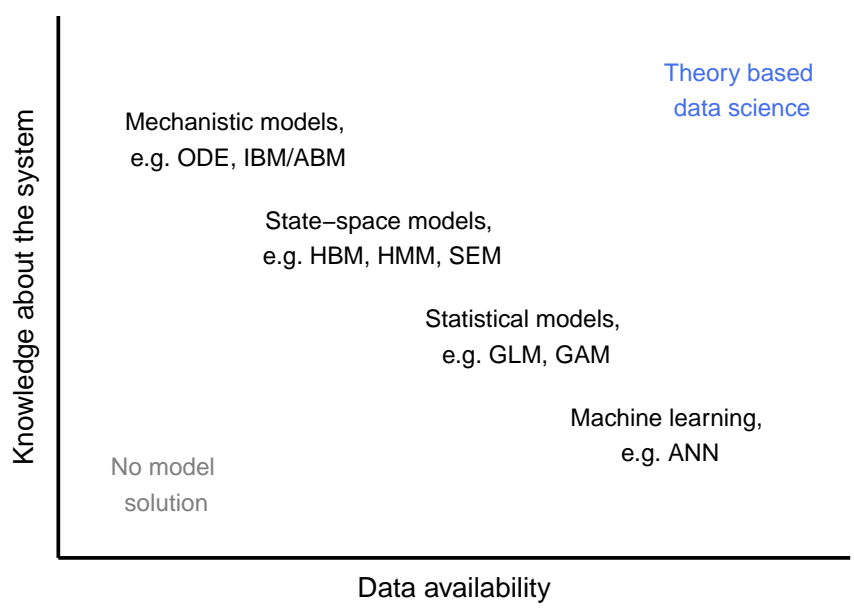

Figure 1: Traditional (black) and emerging (blue) approaches to modeling (adopted and modified from Schuwirth et al., 2019)

reasons for not trusting the quantitative models. They also express concerns that modeling can be expensive or that models can diminish their autonomy and discretion in decision making process (Addison et al., 2013). Most of these misconceptions can be cured with education, improved communication and slowly gained trust among the decision team members.

\subsubsection{Modeling of decisions}

Markov Decision Process (MDP) is a fundamental mathematical model for describing sequential decision making in stochastic environments. The basic idea of MDP is that of an agent positioned within the stochastic environment, which changes its state in response to actions of the agent. The state of the environment affects the reward received by the agent, as well as the probabilities of the future states the environment can transition into. The task of the agent is to select a sequence of actions that will maximize the long-term cumulative measure of reward (Puterman, 1994). MDP models highlight important trade-offs faced by those dealing with management of natural systems: obtaining utility now or improving chances of obtaining utility in the future. This is a very widely applicable problem, because decisions taken in biological and ecological systems affect future state of those systems, as well as the opportunities for learning from them (Williams and Brown, 2016).

The simplest class of MDP models describes fully observable environmental systems with known parameter values. Real life applications, however, mostly deal with partially observable systems under uncertainty, i.e. systems where both the state of the system and the parameter values are unknown (Memarzadeh and Boettiger, 2018). Appendix A summarizes the most common notation of MDP used in the literature (Williams, 2009).

The number of studies utilizing MDP in application to ecology and adaptive management of natural resources has expanded over the recent years. MDP as been applied to different environmental and waterfowl management problems. Memarzadeh and Boettiger (2018) provide an overview of several applications of Partially Observable MDP (POMDP) to population models in ecology. They provide a simplified approach, Planning and Learning for Uncertain Systems (PLUS), which combines POMDP with heuristics for reducing model uncertainty. Fast algorithms for solving POMDP problems exist, easily scaling to systems with hundreds of thousands of states (Chades et al., 2015).

Another variation of POMDP incorporating model uncertainty is called Hidden Mode MDP (HM-MDP). Pozzi et al. (2017) illustrate application of HM-MDP to flooding risk problem under deep uncertainty related to climate change scenarios. Approximate numerical solutions are proposed and challenges related to 
assumptions about future learning are discussed. Depending on whether model weights remain constant or change over the optimization process, the model can represent Passive or Active Adaptive Management.

Most MDP problems (with the exception of the simplest cases) are solved using stochastic dynamic programming. SDP algorithms vary depending on the time horizon of the problem: the "backward iteration" method is useful for finite time horizons, while "value iteration" and "policy iteration" are methods for solving problems on infinite time horizons. Marescot et al. (2013) provide an introduction to MDP for ecologists, discuss software implementations of stochastic dynamic programming and illustrate application of MDP and SDP to wildlife population management.

\subsection{Adaptive management under uncertainty}

Modern waterfowl management is based on fundamental biological understanding of waterfowl populations, combined with statistical advances in monitoring, modeling and assessment of wildlife management decisions (Johnson, 1999). It requires a holistic approach to account for heterogeneity and variability in the environment. Extreme diversity in the nature is exacerbated by our inability to observe and account for the state of biological systems with timeliness and precision required for error-free inferences. Yet another important feature of waterfowl management is that it includes human activity and policies that are implemented sometimes only partially due to limited resources or understanding or both (partial controllability). Finally, biological and social systems falling within the scope of waterfowl management are ripe with structural uncertainty about causal dependencies and biological mechanisms affecting wildlife populations. Scientists may have hypotheses about the processes driving reproduction or mortality of waterfowl approximating it with rough models explaining variability in wildlife population (e.g. the "additive" or "compensatory" mortality model, long debated in waterfowl management. See Appendix B for details of the models).

The adaptive management approach to dealing with environmental problems has evolved over the years (Runge, 2011; Lahoz-Monfort et al., 2014). The simplest form of learning from experience is a "wait and see" approach (precursor to passive adaptive management). The idea is that the observation of natural system, without interfering with it should inform interventions (if and when they become necessary). An even more conservative approach is a "steady state" management, which aims at maintaining status-quo in the environmental system. When it comes to waterfowl management, the "steady state" approach requires upfront agreement on the population targets, and good understanding of population dynamics (including good control over the effects of management interventions through harvest regulation). Unfortunately, environments pertinent to waterfowl management are far from this ideal. Therefore, current management practice often ends up being "objective-based decision making", i.e. management goals (such as "maintenance of harvesting opportunities and protection of waterfowl populations in adverse conditions" documented by Johnson et al. (1993)) are set from time to time and the intermediate actions are directed at achieving that objective. The objectives are set through scientific process of modeling population dynamics and incorporating evidence collected in the process (Williams, 1997).

Literature on adaptive management tends to be concentrated around two main camps (McFadden et al., 2011; Allen et al., 2011):

- Resilience-Experimentalist (RE) school, originating from the work of Gunderson and Holling (Gunderson et al., 2010). Significant focus is placed on gaining understanding of the ecological system under management, in particular advocating the importance of learning about the system's resilience - ability to stay in (or return into) its current state. Projects adopting this methodology build very complex environmental models aiming to capture every detail, potentially significant for the ecosystem. Examples of Adaptive Management projects within this school of research are the Florida Everglades project and the Colorado River (Glen Canyon Dam) projects (Allen and Gunderson, 2011).

- Decision-Theoretic (DT) school, which can be traced back to the work of Possingham et al. (2001) and U.S. Department of Interior (Williams, 1997). This scientific community focuses on defining the problem, clarifying objectives and developing management alternatives prior to building process models (Johnson and Williams, 1999). At the end, the projects following this methodology tend to build less complex environmental models, that solely focus on decision problem at hand. The North American 
Waterfowl Management Plan is a prime example of this direction in research (Nichols et al., 1995; Johnson and Williams, 1999; Johnson and Case, 2000; Johnson et al., 2019).

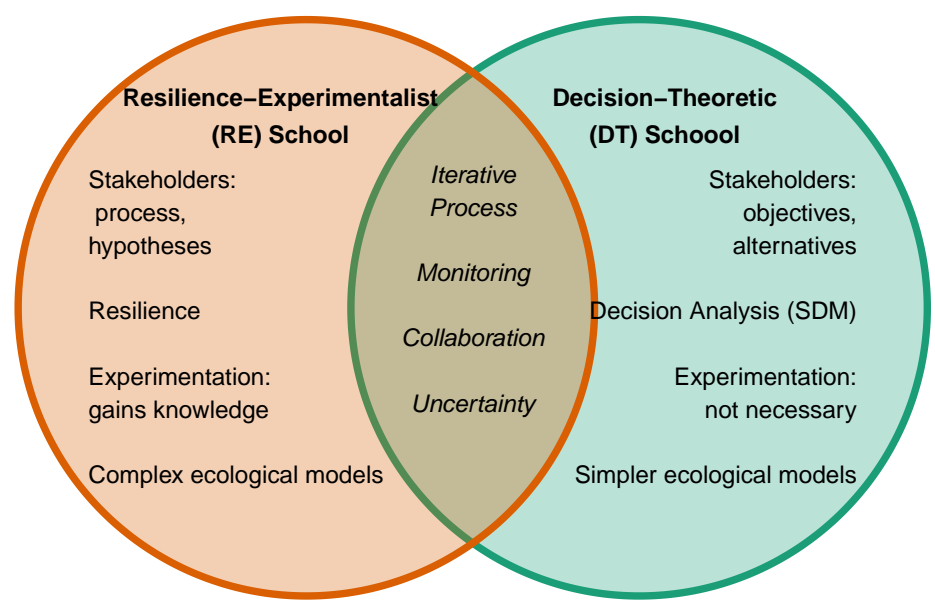

Figure 2: Two main adaptive management schools of thought (adopted and modified from McFadden et al., 2011)

As shown in Figure 2, the Decision-Theoretic school considers Adaptive Management to be an extension of Structured Decision Making (Gregory and Long, 2009), adding four additional elements (Runge, 2011):

- articulating critical uncertainty

- designing and implementing an appropriate monitoring system

- updating the predictive models based on ongoing monitoring information

- adapting future decisions based on the new understanding of how the system responds to management.

Decision-Theoretic school of Adaptive Management assumes that there's a central critical uncertainty impeding decision making. Articulating this uncertainty, then, requires formulation of alternative hypotheses, expressed as multiple predictive models. In order for these models to represent this critical uncertainty, the models should lead to different recommended course of action, or as Decision Analysis would put it, the uncertainty should have a high Value of Information (VOI) (Runge et al., 2011).

Structural uncertainty is expressed in competing Markovian models describing the system, with each model assigned a probability to be the best one ${ }^{3}$. Learning occurs either internally, i.e. through information originating from the management process itself, or externally, where information is coming from experimentation or tracking that is effectively independent of decision making(Williams and Johnson, 2018). Therefore, adaptive management is not about possible change of management action based on future unidentified information, but rather pragmatic, and proactive gathering of the information, which is able change the decision (Williams, 2011a). In this framework, the monitoring effort is targeted specifically at hypotheses that represent the critical uncertainty, efficiently allocating learning resources to only those activities that can improve management. The goal is to compare predictions from multiple models after the intervention, updating belief in the best model that matches the observed response more closely. As the observations accrue, the key uncertainty will be reduced, pointing more assuredly to the preferred course of action (Runge, 2011). Adaptive management therefore, primarily targets structural uncertainty (parameter and model uncertainty) in the environment of partial observability (Chades et al., 2015).

\footnotetext{
${ }^{3}$ Note that this is different from probability of the model being correct.
} 
Rehme et al. (2011) reviewed articles published in Journal of Wildlife Management and Conservation Biology in 2008 to identify research that used multi-model inference, differentiating between "strong inference", where alternative hypotheses are tested in the experiment to falsify those hypotheses and "adaptive inference" that iteratively switches between the objectives of minimizing statistical Type I and Type II errors in different phases of the research process ${ }^{4}$. However ability to carry out such pair-wise comparison across models requires clearly identifiable causal model and separable effects of intervention (often observed in biology and medicine, but less prevalent in ecology and conservation). Adaptive inference maintains multiple alternative hypotheses that are tested through experiments to support a particular line of reasoning. However, results from multiple models remain to be roughly equally plausible (due to uncertainty in model selection) leaving researchers with what is called "weak inference".

Conn and Kendall (2004) note that even modest amount of error in the monitoring data can cause difficulties with the model identification, given that the true model is among the hypothesized alternatives. It is important for the competing models to have similar variance structure and include uncertainty in parameters to reduce bias in the model selection and ensure model weight conversion. There are several approaches of dealing with situation of equivocal results from multiple models:

- model averaging to derive more robust predictions,

- repeat the experiment, postponing the management regime implementation, or

- adaptive management, i.e. accepting management currently optimal alternative and setting up continuous monitoring program to study its effects (Johnson et al., 2015).

Unfortunately cases of "strong inference" are quite rare (Rehme et al., 2011), with most articles reporting "weak inference" results or failing to report the conclusions from multi-model inference at all.

\subsection{Passive vs Active Adaptive Management}

In the Adaptive Management literature distinction is often made between "passive" and "active" adaptive management (Rist et al., 2013a). Active AM deliberately directs management interventions to reduce uncertainty, whereas passive AM treats learning as a byproduct of objective-based management. In practice it often means that active AM explicitly accounts for uncertainty and includes opportunities for learning as part of its management objectives, while passive AM merely accounts for anticipated effect of management actions on natural resources under management, but does not explicitly direct them towards learning. Both approaches recognize uncertainty and use newly acquired information to adjust and improve management policies (Williams, 2011b). Active AM is substantially more expensive to plan and implement and its success is completely determined by the quality of the experimental design backing it up (Gregory et al., 2006).

A method that is quite similar to Passive Adaptive Management and extensively utilized outside of the environmental domain, particularly in capital budgeting, is Real Options Analysis (ROA) (Chades et al., 2015). The main idea of ROA is the valuation of management flexibility through harnessing uncertainties to reap additional benefits compared to a "status-quo" (no-learning) decision. Simple real options problems are solved with stochastic dynamic programming, binomial (or trinomial) lattices and partial differential equations. Higher-dimensional problems, however, require rethinking of ROA as a problem of stochastic switching. Algorithms for solving these types of problems include stochastic mixed-integer programming and Least-Squares Monte Carlo, an approximate dynamic programming method (Chades et al., 2015).

When it comes down to model uncertainty, it is common in passive AM to use one model at a time, deemed to be the most appropriate for given circumstances (Martin et al., 2009). Once the best judged action is implemented, the result from it is used to update the model for future decision making. Management action is, therefore, used to achieve desired result in the resource, not in learning. This approach is characterized by low cost, but also the slowest learning.

\footnotetext{
${ }^{4}$ In science there's a substantial bias against Type I error - False Positives - mistakenly rejecting a no-difference (null) hypothesis, which inevitably leads to higher False Negative rates - failures to reject false null hypothesis. Science should be more concerned about Type II errors - failure to detect response to an intervention - by acknowledging the risks associated with each error type and establishing appropriate thresholds based on deliberate and reasonable trade-offs (Nichols et al., 1995)
} 
A slightly more sophisticated method, compared to the above strategy, is model averaging. Model weights are arrived at using the judgment from previous iterations (current weights) and the best policy (based on pooled results from multiple models) is implemented. Models, representing alternative realizations, are then updated with the system response from the selected management action. This method has marginally higher cost, and slightly higher learning potential.

Active AM embraces learning through deliberate experimentation. In this context, models are picked through experimental design and actions are chosen solely for the purpose of learning. The results from the experiment then dictate which model(s) ought to be used for decision making going forward. Experiments can be repeated later, as needed. Under this approach, resource management objectives take secondary priority compared to rapid learning and come as side-effect of obtaining new information about the ecological system under management.

Model averaging can also be utilized in combination with active AM. The main difference with passive AM is that the predicted responses from alternative models are averaged using the anticipated weights. This is the approach adopted for harvest management of waterfowl population in North America (Nichols et al., 1995; Williams et al., 2002)

Rist et al. (2013a) reviewed literature on AM and concluded that the term is often misunderstood and misinterpreted. They posit that all management learns from the past and therefore the term AM is often used as a synonym for "trial and error" approach. However, in the original work by Walters and Holling (Walters, 2007), a distinction was made between "active adaptation" and "passive adaptation" in an attempt to refocus environmental management practice to proactive experimentation as a method of learning about the system.

\subsection{Failures of AM as failures of management}

The scientific literature is abundant with reports of challenges related to implementation of AM in environmental projects (Schreiber et al., 2004; Walters, 2007; Williams and Brown, 2014; Allen and Gunderson, 2011; Duncan and Wintle, 2008; Walters, 1997; Lee, 1999; Keith et al., 2011; McLain and Lee, 1996; Gregory et al., 2006; Feldman, 2008; Conroy et al., 2011; Johnson and Williams, 1999; Gunderson and Light, 2007; Allen et al., 2011). However, because Adaptive Management in its core is an application of Structured Decision Making with emphasis on iterative decision making in the face of uncertainty (Williams et al., 2009), any failure of AM should first be checked against violation of foundational principles of Structured Decision Making (Keeney et al., 1999) and/or elements of Decision Quality (Matheson, 2005). In other words, it is important to distinguish between failures of AM as methodology (i.e. when application of some other iterative decision making process would deliver better results), as opposed to failure of the management system itself (Rist et al., 2013a).

Table 1, adapted and expanded from Rist et al. (2013b), shows common failures and pitfalls of Adaptive Management, mapping them to the steps of SDM and elements of DQ. Failures of the decision process have been grouped into a separate category, while the rest of the issues map reported AM pitfalls to the deficiencies in key elements of Structured Decision Making and Decision Quality frameworks, respectively. For example "Decision makers fail to understand the need for experimentation and/or monitoring" can be attributed to failure to preform VOI analysis of the additional data collection or experimentation. It can also be signaling a failure of the problem definition, evidencing the misalignment around the decision frame within the team (a situation when different stakeholders understand the decision at hand differently). It is not the AM methodology's fault that the team is not on-board with the need for experimentation. It is most likely the fault of the modeler who have not been able to demonstrate the value of such experimentation and/or an issue with decision frame (either scope, purpose or perspective) (Parnell et al., 2013) that manifests itself in decision maker's unwillingness to sponsor additional monitoring/experimentation. Unfortunately, it might also mean, that the decision maker is, in fact, acting rationally and the value of additional monitoring/experimenting is not there (Nichols and Williams, 2006).

Some issues such as "institutional memory loss" (Schreiber et al., 2004) are typical pitfalls of projects targeting accumulation of knowledge (Rhodes and Dawson, 2013; Fischer and Otswald, 2001), which AM 
projects certainly do (Rist et al., 2013b). In other words, the documented failures of AM projects are primarily related to project definition or the decision process itself, which are pre-requisites to success in Adaptive Management (Williams and Brown, 2018). 
Table 1: Pathologies and causes of failure of AM (adapted and modified from Rist et al. (2013b))

\begin{tabular}{|c|c|c|c|}
\hline Pathology or cause of failure & Refrence & $\mathrm{SDM}^{\mathrm{a}}$ & $\mathrm{DQ}^{*}$ \\
\hline \multicolumn{4}{|l|}{ Planning and decision making } \\
\hline Decision makers fail to understand the need for experimentation and/or monitoring & $\begin{array}{l}\text { Schreiber et al. (2004); Walters (2007); } \\
\text { Williams and Brown (2014); Lee (1999) }\end{array}$ & $\mathrm{C}$ & $\mathrm{L}$ \\
\hline $\begin{array}{l}\text { Risk aversion, reluctance to invest in long-term management, trade-off in present vs. } \\
\text { future value of mgmt experimentation }\end{array}$ & $\begin{array}{l}\text { Allen and Gunderson (2011); Duncan and } \\
\text { Wintle (2008); Williams and Brown (2014); } \\
\text { Schreiber et al. (2004); Walters (1997) }\end{array}$ & $\mathrm{O} / \mathrm{T}$ & $\mathrm{V}$ \\
\hline A focus on planning and discussion (action procrastination) & Keith et al. (2011); Walters (1997) & $\mathrm{E}$ & M \\
\hline Team confusion about who is a decision maker & McLain and Lee (1996) & $\operatorname{Pr}$ & $\mathrm{F}$ \\
\hline Disagreements about 'facts' within a team and about 'objectives' among decision makers & McLain and Lee (1996) & $\mathrm{C} / \mathrm{O}$ & $\mathrm{I} / \mathrm{V}$ \\
\hline $\begin{array}{l}\text { Insufficient attention to building shared understanding and joint decision-making among } \\
\text { diverse interest groups }\end{array}$ & $\begin{array}{l}\text { Gregory et al. (2006); Feldman (2008); Allen } \\
\text { and Gunderson (2011); Keith et al. (2011) }\end{array}$ & $\mathrm{E}$ & $\mathrm{E}$ \\
\hline $\begin{array}{l}\text { Tendency of scientists to overstate ability to measure complex functional relationships } \\
\text { experimentally }\end{array}$ & Gregory et al. (2006) & $\mathrm{C}$ & $\mathrm{I} / \mathrm{L}$ \\
\hline Conflict and self-serving behavior impede leadership, communication and joint action & $\begin{array}{l}\text { Conroy et al. (2011); Keith et al. (2011); } \\
\text { McLain and Lee (1996) }\end{array}$ & $\mathrm{E}$ & $\mathrm{E}$ \\
\hline \multicolumn{4}{|l|}{ Implementation } \\
\hline Difficulty of conducting experiments & Keith et al. (2011) & $\operatorname{Pr}$ & $\mathrm{F}$ \\
\hline $\begin{array}{l}\text { Implementation and monitoring are expensive, inadequate funding for the monitoring } \\
\text { required to successfully compare the outcomes of different management options }\end{array}$ & $\begin{array}{l}\text { Walters (2007); Johnson and Williams } \\
\text { (1999); Walters (1997) }\end{array}$ & $\operatorname{Pr}$ & $\mathrm{F}$ \\
\hline Institutional 'memory loss' regarding what has been already learned & Schreiber et al. (2004) & $\mathrm{E}$ & $\mathrm{E}$ \\
\hline Learning is not used to modify policy and management & Duncan and Wintle (2008) & $\operatorname{Pr}$ & $\mathrm{F}$ \\
\hline Cost and delays associated with gathering information and learning & Lee (1999) & $\mathrm{E}$ & $\mathrm{F} / \mathrm{E}$ \\
\hline Institutional fragmentation: multiple organizations with overlapping mandate & Gregory et al. (2006) & $\operatorname{Pr}$ & $\mathrm{F}$ \\
\hline Lack of leadership and trust & Walters (2007); Gunderson and Light (2007) & $\operatorname{Pr}$ & $\mathrm{F}$ \\
\hline Lack of stakeholder engagement & $\begin{array}{l}\text { Allen et al. (2011); Williams and Brown } \\
\text { (2014); Schreiber et al. (2004); Walters } \\
(2007)\end{array}$ & $\operatorname{Pr}$ & $\mathrm{F} / \mathrm{M}$ \\
\hline Poor execution of study plan & Williams and Brown (2014) & $\mathrm{E}$ & $\mathrm{E}$ \\
\hline \multicolumn{4}{|l|}{ Evaluation and reflection } \\
\hline $\begin{array}{l}\text { Scientists fail to recognize the full range of management options, belief that a single best } \\
\text { policy confers credibility }\end{array}$ & Gregory et al. (2006); Walters (1997) & $\mathrm{A}$ & A \\
\hline Surprises are suppressed & Keith et al. (2011) & $\mathrm{E}$ & $\mathrm{E}$ \\
\hline $\begin{array}{l}\text { Management goals become subordinate to research interests, valuing action more than } \\
\text { learning }\end{array}$ & Lee (1999); Walters (1997) & $\mathrm{O} / \mathrm{T}$ & $\mathrm{F} / \mathrm{V}$ \\
\hline
\end{tabular}

General: E - Decision process execution

SDM Steps: ${ }^{a}$ Pr - Problem, O - Objectives, A - Actions, C - Consequences, T - trade-offs

$D Q$ Elements: ${ }^{*} \mathrm{~F}$ - Frame, A - Alternatives, I - Information, V - Values \& TradeOffs, L - Logical reasoning, M - Committment to action 
Adaptive Management is an example of a double-loop learning (Williams and Brown, 2018) system. The first loop concerns quantities learned through experimentation, while the second loop is calling for periodic re-evaluation of the decision frame through cycling back to the "deliberative phase" of AM (see Figure 3).

Strategic Adaptive Management (SAM) defines a "third-loop" learning, which corresponds to periodic revision of how the AM process is governed (Gillson et al., 2019). This critical self-examination is usually driven by recognition that the current process and decision protocol may not be adequate for addressing emerging environmental and social challenges (Pahl-Wostl, 2009).

Such "three-mode learning" has been developed into the SAM Reflexive Learning Framework (McLoughlin and Thoms, 2015). It is based on defining and re-evaluating Adaptive Resource Management programs starting from high-level objectives, broken down to Thresholds of Potential Concern (TPCs), which are monitored and promptly acted upon as "contingent" decisions.

Notable cases of the implementation success include application of Strategic Adaptive Management in Kruger National Park, South Africa (Gillson et al., 2019). The project team set an acceptable range of variability by defining TPCs, which would trigger an investigation and possibly an action (or revising of TPC level) by the decision makers. This allows flexible iteration time, calling for the subsequent decision milestones only when external conditions change. Such decision policy requires ongoing monitoring and comparing of collected data against TPCs.

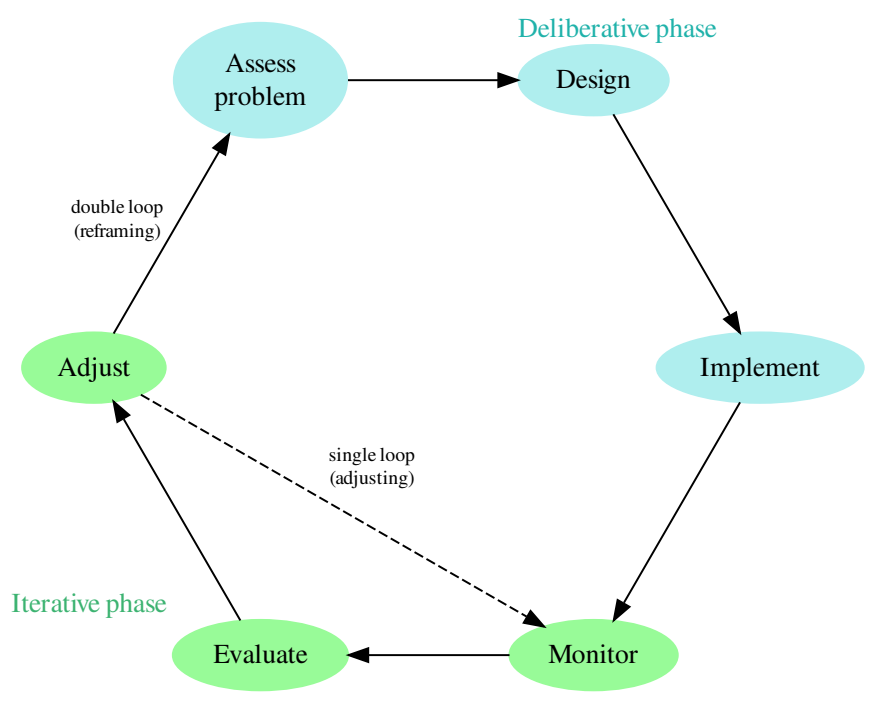

Figure 3: Adaptive Management Cycle (adopted and modified from Williams and Brown, 2018)

\subsection{Adaptive management and VOI}

Adaptive management integrates alternative hypotheses about system dynamics (structural uncertainty) and responses to potential interventions into a decision making framework, providing a method for refining and updating system models through feedback, captured in regular monitoring. Decision-analytic methods can guide allocation of management resources to identify topics of research with the highest value of information, i.e. those that matter most in the choice of management actions (Runge et al., 2011). A gradual learning and adaptation approach to decision making attempts to balance the efforts spent on learning about the environmental system and actually managing it (Moore et al., 2017). This trade-off, often called "dual-control problem", highlights a dilemma faced by decision makers: balancing cost of learning (including opportunity cost associated with drawing resources from the main activity of managing the environmental resource in question) against the benefits of applying the learning in the future.

There are two key properties of information used for decision making: whether it can alter the preferred course of action (management alternative) and whether information can be improved through additional data 
collection (monitoring). Information can be valuable because without it a different management action is preferred under two different hypotheses (models). If the the wrong action is taken, the expected performance will be lower and therefore, decision maker will suffer an "opportunity loss" (Raiffa, 1970; Runge et al., 2011).

Information is obtained through monitoring (with or without the experiments to accelerate learning). The Value of Perfect Information forms the "upper limit" of the investments reasonably justified to be invested into learning. In practice, however, efficacy of learning is less than perfect and therefore most of the time only a few of the uncertainties can get resolved (which is measured by Expected Value of Partial Information) (Williams and Johnson, 2015). Learning often occurs through imperfect "sampling" of data obtained through monitoring, where parameters of statistical distributions, from which data are assumed to be drawn are estimated from statistical samples. In these situations, we can guide our monitoring efforts by Expected Value of Sample Information, EVSI (Runge et al., 2011). Regardless of the type of information in question, the main idea is that the experimentation makes sense only if its benefits outweigh the costs, otherwise decision maker should accept the risks and proceed to managing the environmental resource in the face of uncertainty.

Adaptive Management combines monitoring with management and allows accumulated learning to affect future decisions. The two schools of AM differ substantially with regards to the types of uncertainty they are addressing. The Decision-Theoretic school of AM is focusing on "known unknowns" - those uncertainties that can be described upfront and evaluates whether reduction of such uncertainties can improve management. The Resilience-Experimentalist school of AM tries to address not only these characterizable uncertainties, but also those that currently can not be articulated and seeks to set up monitoring to adapt to unanticipated events. The DA school believes that AM is justified only if there's an uncertainty that impedes a decision. The RE school finds it more challenging to assess the value of AM, due to difficulties to quantify the importance of unidentified uncertainties (McFadden et al., 2011).

A Structured Decision Making approach can therefore be used to assess the value of Adaptive Management programs and investments into monitoring. Moore and Runge (2012) followed a structured approach to evaluate adaptive management resource allocation for controlling invasive willow Salix cinerea in alpine Australia. The spatially-implicit state-base dynamic model included 8 groups of parameters and evaluated 57 different resource allocation strategies across 13 different budget levels. The result helped prioritize the efforts focusing on the areas most vulnerable to the invasive species (bogs) and only then moving towards more distant targets, as the budget increased. The VOI showed that learning about the system is unlikely to improve management, because the same strategy (treating bogs) is optimal across a wide set of parameters (Moore and Runge, 2012). Results of the VOI analysis are conditional upon the context of the decision (decision frame), choice of the value metric (objectives), and the set of management actions it considers. Other factors affecting the result are choice (and structure) of model and specific parametrization (Runge et al., 2011).

Monitoring in AM can pursue several goals (Lyons et al., 2008):

- inform state-dependent decisions for the next decision cycle (e.g. estimate waterfowl population size or composition to set harvest policy)

- assess the effectiveness of the actions undertaken in the previous decision cycle (e.g. assess the effectiveness of changed hunting regulations)

- collect observational evidence in support of competing models of the system with the aim of improving management in the future (e.g. investigate whether the harvested waterfowl population is best described by a compensatory or an additive mortality model)

- perform a controlled experiment (intervention with an aim of collecting data) to validate certain hypotheses about the system dynamics (e.g. test different scaring devices to defend agricultural crops from foraging geese)

Monitoring programs that do not have clearly defined goals (and management actions that depend on the outcomes of such monitoring) are running a risk of irresponsible resource use. Williams and Johnson (2017) discussed a formal approach to Adaptive Management with regular monitoring and re-evaluation of decision strategy in the settings with structural uncertainty and partial observability. They found limited value in programs that include monitoring that is done too frequently (Tulloch et al., 2017). 


\section{Waterfowl management under uncertainty}

\subsection{What has been done}

\subsubsection{History of waterfowl management in North America}

The North American waterfowl management program is arguably a hallmark of structured and systematic approach to environmental resource management. It rests on comprehensive animal population monitoring programs, and includes international flyway-scale wildlife research and management working groups, maintaining state-of-the-art population models and advising harvest regulation across the continent (Nichols et al., 1995).

Waterfowl harvesting remained unregulated up to 1918 when the Migratory Bird Treaty Act was signed by Canada and the U.S. to protect declining populations through establishing seasons closed for hunting (primarily during breeding), as well as a complete hunting ban for species on the brink of extinction. The period of 1930 to 1950 was characterized by the trial-and-error harvest regulation guided by common sense notions, for example that hunting mortality drives the populations down and improved habitats contributes positively to waterfowl abundance. By 1975 a lot of data collection programs had been established, including aerial surveys, detailed harvest mail-in surveys, functioning banding and band-recovery programs for estimating harvest and survival rates, as well as wintering grounds survey for assessing post-breeding abundance and distribution. Recoveries of banded birds provided an understanding of migratory paths, which was used to delineate the main flyways through the continent. Responsibility for flyway-specific management was shared among its states and provinces. New methods of testing the relationship between hunting and overall mortality were introduced in late 1970s. The compensatory mortality hypothesis was formulated for duck populations, which posits that within a certain range of mortality values, overall mortality remains unchanged even though hunting mortality might change. For example, in the years of more restrictive hunting regulation, under additive mortality higher survival rates should be expected, whereas compensatory mortality anticipates no change in survival rates (Nichols, 1991). The nature of the relationship between hunting and overall mortality matters, because depending on the adopted hypothesis, it can lead to very different optimal harvest policies (Pöysä, 2004; Pöysä et al., 2013). In 1980s spatially explicit models of waterfowl habitats were developed to relate various habitat management initiatives to changes in reproductive rates. The North American Waterfowl Management Plan (NAWMP) introduced in 1986 stipulated that the stability of waterfowl populations is conditional upon restoration of wetland ecosystems and listed population goals for a number of most important species (Nichols et al., 1995). In response to continuing controversy regarding the setting of waterfowl hunting regulations, U.S. Fish and Wildlife Service adopted a formal Adaptive Harvest Management (AHM) framework, aiming to increase effectiveness and transparency of waterfowl harvest decisions in the face of uncertainty. Five years later Johnson and Case (2000), reviewing the successes and the failures of the adopted process, concluded that despite high expectations that AHM would serve as "panacea" for eliminating all contention and frustrations surrounding waterfowl harvests, much uncertainty remained unresolved and in some cases controversy has actually increased. The authors wrote:

\footnotetext{
"Because of the explicit and formal nature of the AHM process, managers are being forced to question long-held beliefs about their ability to understand and influence the managed system, and about the potential of biological science to engender policy consensus. We characterize these traditional beliefs as myths of control, learning, and goal setting."
}

Myths of control are related to environmental managers' ability to control the waterfowl population structure and size through hunting regulation. Much of the variability and diversity remains outside of waterfowl managers' area of influence. Greater biological understanding of demographic variation and its causes comes at an exponentially increasing cost of managing target populations at increasingly finer organizational, spatial and temporal scales. Myths of learning are related to ability to acquire knowledge from observational data (as opposed to formal experiments with replication, randomization and experimental controls, which in many cases of waterfowl biology are not feasible) and that target biological and social systems are stable enough to 
permit learning. Myths of goal setting are related to the belief that broad qualitative management objectives can result in unique and unanimously accepted management policy (Johnson and Case, 2000).

Lefebvre et al. (2017) takes the reader through the history of the greater snow goose Anser caerulescens atlanticus population expansion in the 1990s and related management actions undertaken by the U.S. and Canadian environmental agencies and regulatory bodies to contain the population growth. Increase in abundance of geese was triggered by the changes in the overwintering pattern by the greater snow geese in response to the climate change and the expansion of agricultural landscapes in Canada and the USA. This in turn reduced goose exposure to traditional hunting locations and necessitated changes in the hunting regulations in agricultural landscapes. The problem was recognized as early as 1996, and the recommendation was put forward by the newly created Arctic Goose Habitat Working group to stabilize the greater goose population between 0.8 and $1 \mathrm{mln}$ birds by 2002. This work triggered several important management actions both in Canada and in the U.S., including spring conservation harvest in agricultural landscapes which was unprecedented since signing of Migratory Bird Conventions in 1916, which specifically prohibited migratory bird hunting from March to August. It was argued that Spring Harvest shall be considered a conservation strategy aimed at protecting goose habitats from overdepletion. These efforts resulted in the greater goose population stabilizing in the range of 0.7 to $1 \mathrm{mln}$ birds, which is the level maintained today. The authors conclude the historical survey by noting that the same factors that led to the explosive growth in population of greater snow goose are still present today (changes in climate conditions towards warmer climate, high availability of food in the agricultural landscape and opening of new habitats), which poses a risk of renewed population growth and the need for additional management actions (Roberts et al., 2018).

The North American duck populations are managed on the flyway scale. Generic duck management plan is based on the population dynamics of mallards Anas platyrhynchos. Specialized plans have also been proposed, such as the plans for scaups Aythya affinis/marila and northern pintails (Nichols et al., 1995). There is a trade-off between degree of management plan specialization and incremental cost/complexity of managing the population, which managers need to evaluate before adopting a new species population model (Johnson et al., 2015).

\subsubsection{History of waterfown management in Europe}

Geese population were on rapid decline in Europe in the beginning of 20th century due to loss of natural habitats and extensive hunting in the formerly native wintering and stopover areas. However, strict hunting regulations and creation of wildlife refuge areas in 1950s turned this trend around and populations of most geese species started growing again (Fox and Madsen, 2017). The growth was further fueled by the development of agriculture, making nutritious, although sometimes less balanced, food sources abundant for the migratory waterfowl (Fox and Abraham, 2017). Changes in the climate and land use, combined with the successful conservation efforts, contributed to emergence of a human-wildlife conflict related to geese foraging in agricultural landscapes of Central and Northern Europe (although air flight safety, public health and ecosystem effects are also often cited as areas of concern).

African-Eurasian Waterbird Agreement (AEWA) is an international intergovernmental treaty established with the aim of conservation of migratory birds across Range States in Central Asia, Middle East, Africa, Europe, Greenland and the Canadian Archipelago. The Agreement originally established by 14 states came into effect on 1 November 1999. Today the agreement includes 80 countries as Contracting Parties and covers the area (Non-Party Range States) of another 39 countries (AEWA, 2020). In 2009 the Parliament of Europe together with the Council on the conservation of wild birds issued a Directive 2009/147/EC commonly known as the EU Bird Directive, which mandates that Member States of EU shall maintain the populations of European bird species at a level that "corresponds to ecological, scientific and cultural requirements" (Madsen et al., 2015b), accounting also for economic and recreational needs. The Guidance Document regulating hunting in Europe, known as the Hunting Guide issued by EU commission in 2008 interprets the requirements of the Bird Directive and establishes mechanisms for coordinating science-based management of waterfowl harvests in Europe (Madsen et al., 2015a).

AEWA provided a management framework for conservation of over 500 populations of water birds, mandating use of sustainable hunting practices following the principles of Adaptive Harvest Management. In 2011-2012 
AEWA initiated implementation of coordinated harvest management initiatives for Svalbard pink-footed goose Anser brachyrhynchus (Madsen et al., 2017) and taiga bean goose Anser fabalis fabalis. AEWA adaptive management projects from the very beginning were determined to learn as much as possible from the experience of the U.S., aiming at establishing scientific, transparent and efficient decision framework for managing waterfowl populations across Range States. The very first report on sustainable management of huntable migratory bird contained significant technical contributions by Fred A. Johnson of U.S. Geological Survey, providing background for waterfowl conservation and harvest in the USA and outlining Adaptive Harvest Management framework along with basic information requirements for modeling (Madsen et al., 2015b).

In 2016 members to AEWA have mandated the establishment of European Goose Management Platform, a working group for developing and implementing sustainable waterfowl management plan for European goose populations. European Goose Management International Working Group (EGM IGW) convenes annually to review evidence, ratify decisions and draft goals for the next adaptive management cycle. The collaboration within AEWA and EGMP is well underway, demonstrated some successes (initiated development of management plans for Barnacle and Greylag Goose populations; implementation of International Species Management Plan for Pink-footed Goose and Taiga Bean Goose) and identified certain challenges. On a national level, communication between various government bodies and institutions is important. It is primarily a question of who has ultimate decision mandate (typically shared between different parties for different aspects or waterfowl management) and political/financial responsibility for the problem and its solutions. Securing public support through communication and collaboration with non-government actors can ensure common perspectives and constructive collaboration with land owners and opinion leaders. On an international scale, although European Bird Directive and AEWA provide formal framework for collaboration, level of engagement of different states varies. In this situation, coordination of efforts can ensure various working groups act in concerted manner, maintain scientific basis for decisions and do not produce unintended policy consequences for the colleagues in a neighboring task force. Also, level of financial commitment to funding of joint activities falling within AEWA varies across Range States. This issue is closely related to funding of monitoring efforts, as these costs typically fall within responsibilities of national governments (Stroud et al., 2017).

Duck research in Europe is not as mature, as it is in North America. One of the critical issues still actively studied is delineation of migratory flyways for European duck populations (Holopainen et al., 2018). There's also limited understanding of causal mechanisms behind decline in most duck populations: changes in survival or deterioration of reproductive success. The range of alternatives (management options) applied to duck population management has also been historically limited: protection of habitats (via establishment of conservation areas) and/or hunting season regulation. The policy in most cases has been that species are subject to hunting, largely without restrictions, until population crosses a threshold set by AEWA (indicating severe risk of extinction), upon which a drastic measure, such is permanent protection, is implemented. Until today, most countries lack legislative infrastructure for restoring population before the critical threshold is crossed.

While North American duck population assessment is based on breeding season surveys and (to a lesser extent) winter surveys, European duck research relies almost exclusively on mid-winter post-harvest assessment of duck populations and their approximate distribution across wintering grounds. Estimates of total population are impeded by gaps in ringing-recovery data and inability to differentiate between natural and hunting mortality (Elmberg et al., 2006). Holopainen et al. (2018) survey European duck populations and propose teal, wigeon, and goldeneye as three most promising species for introducing Europe's first adaptive management program for ducks (population statistics for mallard, the most numerous species in Europe, are biased by farmed mallards released annually prior to hunting season), which could complement AEWA efforts for European goose populations. As the case was in North America, models can be built and Adaptive Management program can be introduced for selected few species with a goal to later extended it to other populations. 


\subsubsection{Human-nature conflicts and management objectives in waterfowl management}

Last 100 years were characterized by rapid intensification of agriculture and expansion of cities worldwide, but especially by Europe and North America. As a result, increasingly often we find waterfowl settling in urban landscapes including parks and coastal recreational areas, which offer perfect combination of rich and reliable feeding sites, safety from predators and proximity to open water with convenient nesting opportunities yearround. Presence of geese in urban landscapes raise concerns about contamination and parasite transmission in public areas, potentially posting a threat to public safety and biodiversity (Fox, 2019).

Geese are very mobile and can be spotted hundreds of kilometers away from their usual habitats (Nilsson and Hermansson, 2019). Outside of cities, geese foraging on agricultural crops cause structural damage to plants (either through direct removal of plan parts or through trampling of young greens into the ground) and alter the aeration and temperature/moisture balance of the top soil layer by compacting it with their feet ("puddling"), all of which can affect plant growth. Another concern is significant amount droppings geese leave on pastures and agricultural landscapes, although fouling of soil is partially offset by fertilizing effect of droppings and enhanced nutritional properties of grass (Fox et al., 2017).

Precise and cost effective method of assessing real reduction of crop yields caused by grazing geese has been considered an insurmountable challenge for the last 30 years (Owen, 1990). Many waterfowl researchers make no distinction between actual and perceived damage, rather treating it as indication of conflict between interests of geese and farmers. Many governments attempting introduction of loss compensation schemes, find themselves deeply involved in the conflict, as the frustration about geese foraging in agricultural landscapes become aggravated by the social conflict surrounding compensation funding (see Bainbridge, 2017, and Eythórsson et al. (2017) for experience from Scotland and Norway, respectively).

When formerly migratory geese become year-round residents (as the case is in Northern Europe), they affect biodiversity of natural habitats, especially in areas of high-density settlements (Stroud et al., 2017).

Growing number of geese settling close to or within urban areas pose significant risk to aviation (Stroud et al., 2017). Risk of aircraft collision and damage by geese during take-off and landing is substantial, especially in locations where airport space is neighboring open waters (Bradbeer et al., 2017).

Any progress in waterfowl management attempting to resolve any of these conflicts, requires clear statement of management objectives and formulation of measurable metrics for comparing management choices (decision alternatives) and assessing policy performance (Nichols et al., 1995). The task of formulating unambiguous objectives is central to SDP and the MCDA in general. Below are some of the waterfowl management objectives mentioned in the literature.

- Stable and sustainable population size. European Bird Directive sets protection of natural environment and conservation of the wild bird species as top priorities, as these contribute to the societal objectives of better living conditions and sustainable development (European Parliament and Council of the European Union, 2010). Population size is estimated by assessing waterfowl abundance via mark and re-sight programs (Ganter and Madsen, 2001; Sheaffer and Jarvis, 1995; Clausen et al., 2019) and by direct observation (Bibby, 2000; Aceves-Bueno et al., 2015; McKinley et al., 2017).

- Threat to public health and safety. Waterfowl settlements close to residential areas can pose a threat to public health and safety due to fouling/contamination and exposure to diseases/parasites, which often accompany waterfowl populations (Fox, 2019).

- Cultural/recreational value for birdwatchers and tourists. Waterfowl settling in urban areas attract visitors to parks, wildlife refuges and recreational areas along shorelines (Fox, 2019). Swans, ducks and geese settlements serve as natural attraction boosting tourism and supporting local economy.

- Conservation activism. Geese and ducks are often picked by environmental activists as "flagship species" for protection (Gunnarsson et al., 2013).

- Tundra degradation in breeding range. Increased abundance of geese leads to excessive exploitation of vegetation on breeding grounds resulting in degradation of tundra habitats (Williams and Madsen, 2013).

- Conflict with agriculture. Environmental authorities in Norway have established a subsidy scheme for farmers affected by goose refuges established on their land. The amount of subsidy is aiming to 
compensate the farmers for the actual crop yield loss due grazing (Eythórsson et al., 2017; Fox et al., 2017).

- Hunter recreation opportunities. Recreational hunters represent an important resource in waterfowl management, since most of the adaptive harvest management plans rely on them for achieving target harvest levels and maintaining stable waterfowl populations (Williams et al., 2019).

- Long-term aggregate harvest. One of the most important objectives of Adaptive Harvest Management is maximization of long-term harvest, which is achieved through establishing sustainable harvest rate (Johnson et al., 1993).

- Annual hunting season length. Prolonged hunting season allows greater flexibility in achieving target harvest values (Johnson et al., 2019).

- Frequency of changes in regulation. Frequent changes in the hunting regulations may increase confusion among hunters and discourage them from participating in the harvest. Stable regulatory environment contributes to predictability and increases chances of achieving population targets (Johnson et al., 2019).

- Risk to air traffic safety. Large-bodied waterfowl (geese, swans) settlements in immediate proximity to airports pose the risk to the air traffic, increasing the risk of collisions between aircraft and flocking birds (Bradbeer et al., 2017).

- International treaties compliance. Compliance with the international treaties and agreements on conservation and sustainability is, in many cases, the primary target of adaptive management plans for participating countries (Nichols et al., 1995).

In multi-species duck harvesting decision (Johnson et al., 2019) the Atlantic Flyway team wanted to maximize four of the objectives listed above (aggregate harvest, season length, frequency of change in regulation, and breeding population size) and established the trade-off weights using swing-weighting method (Goodwin and Wright, 2014) to be used in multi-criteria decision analysis (Keeney and Raiffa, 1976).

International Species Management Plan (ISMP) for Svalbard population of Pink-footed Goose adopted four objective out of the list above: maintain sustainable population size, limit agricultural conflict, protect tundra and create recreational hunting opportunities (Madsen et al., 2012).

There's a research need for systematic review and synthesis of the management objectives (including differences in perspectives among different stakeholder groups) for waterfowl management problem, organized into the objectives hierarchy (Keeney and Raiffa, 1976) or value map (Raha, 2010).

\subsubsection{Management responses and alternatives}

There's a wide selection of management responses to crop damage by geese documented in the literature (Fox et al., 2017; Stroud et al., 2017), which can be roughly organized in the following categories:

- Harvest. Reducing crop damage by reducing goose population. Although harvesting is perceived to be a natural solution to the increasing population of waterfowl, shooting may aggravate the conflict between geese and agriculture instead of solving it (Bauer et al., 2018).

- Disturbances and deterrents. Persistent disturbances (scaring) can make valuable crops energetically-expensive for geese. Improvement of habitats for predators can be an effective tool to deter geese from foraging on pastures.

- Provision of alternative feeding areas. More nutritiously attractive sacrificial crops planted in larger less-disturbed areas can alter geese pecking order or crops to forage on.

- Compensation to farmers. Compensate farmers to host geese on their land and accept associated damage.

- Coordination of attractive fields. Perform regional planning of natural reserves and refuges and distribution of subsidies on regional scale to increase efficiency of geese management.

- Stakeholder engagement and co-management. Involve farmers in development of tools and methods of dealing with foraging geese to reduce level of conflict. 
There's a wide selection of non-harvest response strategies for deterring geese from settling in urban locations and in the areas open to air traffic, including removal of food supply, removal or limitation of access to water bodies, use of acoustic and visual deterrents, use of chemical repellents, trapping for relocation, destruction of nests and chemical contraception (Fox, 2019; Bradbeer et al., 2017).

One strategy for reducing human-wildlife conflict is designating landplots for unhindered foraging. The assumption is that wild waterfowl would "learn" to differentiate between the plots where deterring devices are engaged (including preventive shooting) and choose to forage primarily on designated landplots. However, the recent study by Koffijberg et al. (2017) did not detect change of behavior for various species of geese wintering in the Netherlands after introduction of "protected foraging" areas. The authors also could not detect any "learning effect", which could be manifested in the increased number of geese using the designated areas. The authors hypothethise that lack of response could be attributed to irregular shape and location of designated areas (sometimes enclosing plots of non-designated areas, as the participation of landowner farmers was voluntary) and the lack of consistent scaring in the rest of the areas, since compensation for losses caused by wild geese was available to both participating and non-participating landowners.

Many scholars suggest that the effectiveness of scaring is understudied (Fox et al., 2017). Recent study by Simonsen et al. (2016) for pink-footed goose spring staging area in mid-Norway investigated a dose-response relationship between amount of scaring and geese use of agricultural crops and concluded that scaring is only effective when done consistently and continuously (5 times a day or more), with most effect evident in the first week of scaring.

\subsection{Models in waterfowl management}

\subsubsection{Harvest (Population models)}

Adaptive harvest management is an iterative process of decision-making under uncertainty based on wellarticulated management objectives, specified regulatory alternatives, and prediction of regulatory impacts based on alternative hypotheses (and associated models) of system dynamics (Nichols et al., 1995). Formally AHM can be viewed as a recurring stochastic control process, where the state of the system (e.g. a set of population characteristics) is periodically observed and certain management actions (e.g. hunting regulation) are implemented. As a result some immediate benefits (e.g. harvest) are received and some (management and monitoring) costs are incurred, both of which are relevant to the long-term management objectives (Johnson and Case, 2000).

Harvest decisions are set within the context of waterfowl biology, of which population dynamics is single most important factor. Population models include both growth models, such as the Beverton-Holt or the Ricker stock-recruitment models (Ricker, 1954; Williams et al., 2002), as well as process models with explicit demographic dynamics (Caswell, 2001). In these models objective is often defined in terms of species viability (risk of extinction) or population abundance (possibly with a threshold), while uncertainties are related to demographic parameters of the model (e.g. survival, productivity) or the model structure itself (LahozMonfort et al., 2014). Models are relevant for the decision at hand, when different management actions are able to generate different responses and provide additional understanding of the population dynamics through learning.

Passive AHM consists of 3 steps taken on annual basis (Johnson and Case, 2000):

1. Identify optimal regulatory action, based on the knowledge about the state of the system (e.g. population characteristics) and the weights of the alternative models

2. Given the optimal regulatory action, determine model-specific projections of population size

3. When next year's monitoring data is available, adjust model weights according to individual model's ability to predict the change in population

Williams et al. (1996) used simulation model to study the effect of harvest rate, partial observability and partial controllability on reduction of structural uncertainty in adaptive harvest model of North American 
mallards. The objective of the study is to characterize and predict changes in population based on compensatory and additive hypotheses. Predictions are then compared to real (or simulated) data to see which model performs better at accommodating population dynamics observed through monitoring. Results from the study suggest that harvest rate can be used for discriminating between alternative mortality hypotheses.

Population model in Williams et al. (1996) included several specialized modules which contributed to understanding of key uncertainties: abundance of ponds (habitats), reproduction rate (as a function of pond conditions and size of breeding population), harvest rate (randomly varying around the intended rate) and population dynamics (adults, recruitment of surviving offsprings into adult population, adult mortality from harvest and other causes, population monitoring). These variables feed into the predictor models (using different survival hypotheses) and perform Bayesian updating of the model weights based on their ability to predict actual changes in population. The overview of the annual life cycle and mortality of mallards is provided in Figure 4.

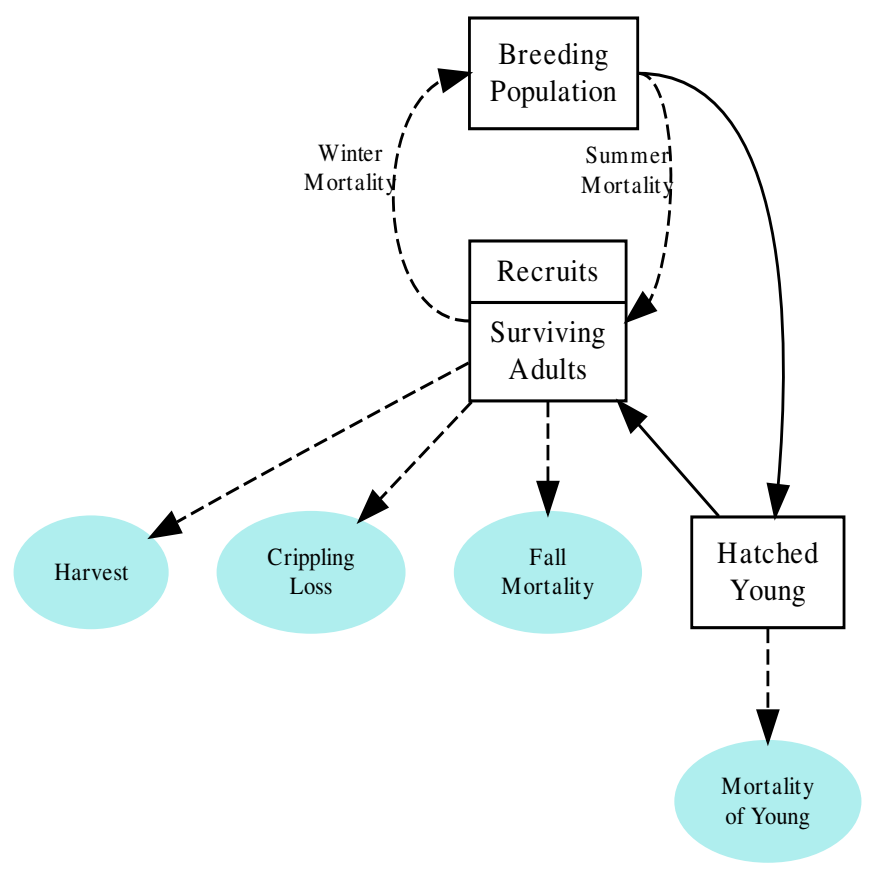

Figure 4: The annual life cycle of mallards (adopted and modified from Williams et al., 1996)

There are some structural uncertainties and issues specific to adaptive harvest management of waterfowl:

- "additive" vs "compensatory" mortality hypotheses (see Figure 5). If harvest mortality simply adds to other sources of mortality then increase in harvest rate would have direct effect on survival. But if changes in harvest mortality are partially offset by changes in other sources of mortality, then harvest mortality is considered to be compensatory, at least within some range of harvest rate values. See Appendix B for details of the two models.

- use of "scalar" vs "individual" models to account for individual differences in vital rates (survival, fertility) and response of those to exogenous perturbations (e.g. harvest). The middle ground is "structured population models" (Cooch et al., 2014), although even "scalar models" (disregarding the age structure) might may be able to effectively account for the waterfowl population dynamics (Johnson et al., 2018).

The duck populations are more sensitive to shifts in reproductive success than to changes harvest mortality(Johnson et al., 1993; Johnson and Case, 2000). Therefore focus should be put on mechanistic models capturing density-dependence of mortality and reproduction processes on duck biology (Gunnarsson et al., 
2013). Density dependence is related to specific properties of the habitat (heterogeneity and individual quality), as well as the crowding effects emerging as a result of rise in population density, manifesting itself in limited per-capita availability of critical resources, such as food, nesting sites, etc. (Elmberg, 2003; Lindström et al., 2005).

Adaptive harvest model for mallards Anas platyrhynchos is based on four competing population models representing the combination of two reproductive and two survival hypotheses (Johnson, 2011). The mortality hypotheses express alternative views on the effect of harvest of annual survival. The reproductive hypotheses capture different view on the decline in per-capita reproductive rate accompanied with increased population abundance (i.e. density-dependence). Initial (equal) model weights get updated based on annual monitoring data with posterior model weights shifting significantly in support of weak density dependence and additive mortality hypothesis, as predictions from these models consistently produced population estimates that were able to more closely match actually observed data (Johnson et al., 2015).

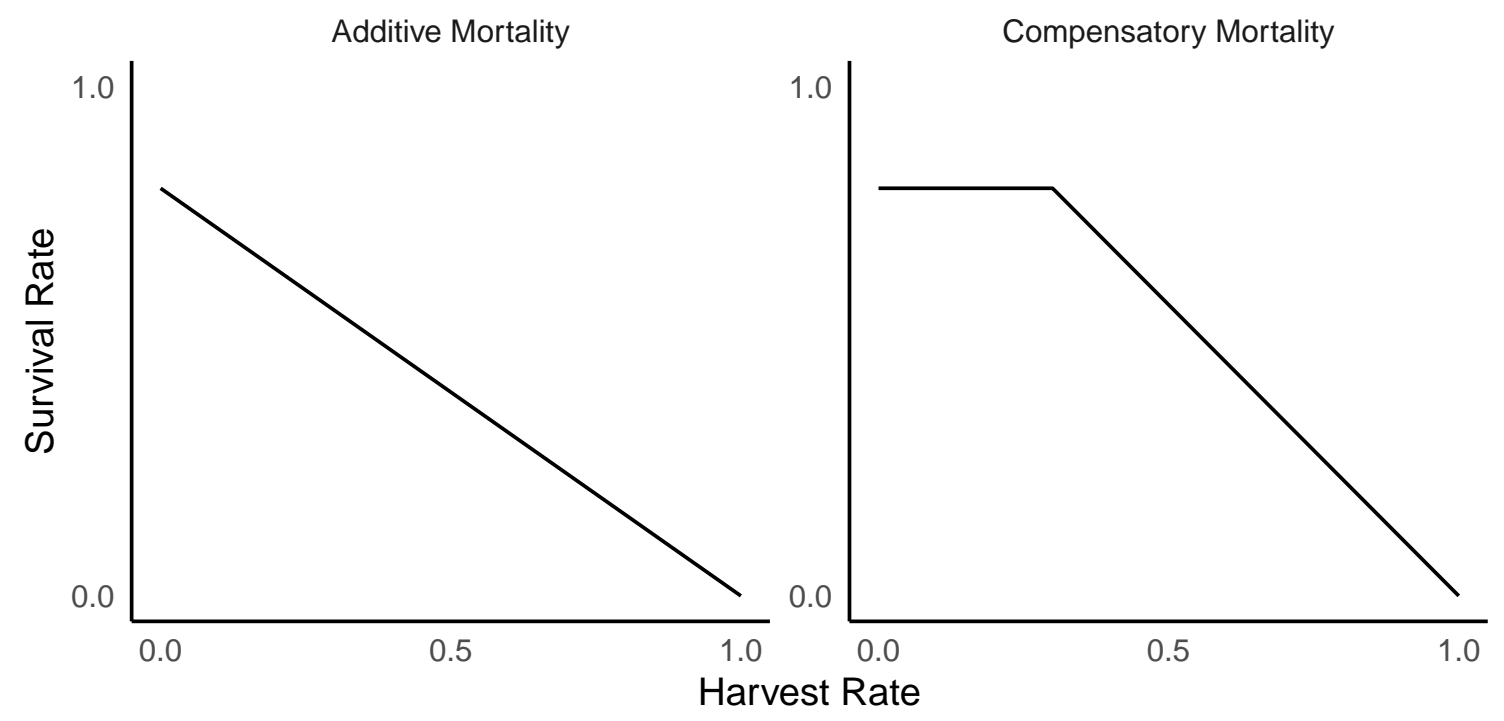

Figure 5: A simplified form of additive and compensatory mortality hypotheses (adopted and modified from Williams et al., 1996)

Although multi-model inference is usually performed to identify the model best fitting the existing data, predictions from such models may be constrained by the time period for which the data about survival, reproduction and other relevant covariates are available. In certain cases the behavior of the models outside of the range of the previously observed data is more important for developing robust management policy. Johnson et al. (2014) built 9 models as a combination of three alternative hypotheses about survival and three hypotheses on reproduction. For non-hunting mortality the models assumed: (1) survival is randomly varying through the years, (2) survival is weather-dependent, (3) survival depends on weather and total population at the start of the year (density dependent). Same assumptions were made about reproduction, except density-dependent reproduction hypothesis used sub-adult and adult geese count instead of total population. Carrying capacity was also varied across models. Predictions from the nine models were used in long-term harvest decision model optimized using SDP. Survival was estimated from capture-mark-resight data in a manner similar to analysis in van der Jeugd and Kwak (2017) performed for Dutch Northern Delta barnacle geese (Burnham, 1993). Robust decision policy was derived both using maximin criterion and by selecting the policy that performs well despite model uncertainty. The analysis suggested substantial density-dependence and relatively small VOI for eliminating model uncertainty (only around $3 \%$ of the objective value). The Value of Information in this case represents the difference between the best policy should the most appropriate model were know, and the best policy assuming equal weighting of the nine models (i.e. with model uncertainty). Similar results were shown in Smith et al. (2013) where management policy for sustainable harvest of horseshoe crabs in Delaware Bay was generally unaffected by the choice of 
the model, explaining the relationship between spawning of crabs and vital characteristics of migrating red knots.

Another way of modeling sustainable harvest level is through Potential Biological Removal (PBR) framework (Johnson et al., 2012) and its generalization the Prescribed Take Level (PTL) (Runge et al., 2009). The framework has been successfully applied to modeling of harvest and illegal take of birds. Koneff et al. (2017) applied PTL framework to modeling allowable harvest level of North American sea ducks as a function of intrinsic rate of population increase $r_{\max }$ and a density-dependent parameter $\theta$. The main challenge of PTL model is accurate estimate of $r_{\max }$, which can be assessed using demographic- invariant methods, depending only on assessment of adult survival rate and age-at-first-breeding (Niel and Lebreton, 2005).

Age-structure of the hunting bag might also have a significant impact on population dynamics. Relatively high share of juveniles in Norwegian harvest has smaller effect on population than the respective hunting efforts in Denmark, where share of adult birds in the hunting bag is higher (Clausen et al., 2017). Successfully implementing sustainable harvest regulations requires collaboration between science, farmers and hunters communities on flyway scale (Madsen et al., 2015a).

In international setting, opportunities for adaptive management are constrained by stakeholder complexity. For example in the process of agreeing the International Species Management Plan (ISMP) for the Svalbard pink-footed goose Anser brachyrhynchus representatives from flyway countries negotiated a "population ceiling" of around 60000 individuals (with acceptable variance of $+/-10000$ individuals, spring population size) and included this target into the objectives hierarchy (Madsen et al., 2017). The population target is a utility threshold (Martin et al., 2009) serving as a proxy for a various of objectives held by stakeholders that helps alignment and serves as a starting point towards reaching a consensus on difficult environmental problems (Williams and Madsen, 2013).

There's a research need for a coherent set of ecology and decision thresholds taking into account relevant uncertainties (Martin et al., 2009) to complement the population targets set by the current and future ISMPs to guide decision making around adaptive management of European waterfowl populations.

\subsubsection{Habitat (Spatial models for waterfowl movement)}

Maintenance and improvement of wildlife habitats is one of the key objectives of EU Bird Directive (European Parliament and Council of the European Union, 2010). New areas for habitat are allocated with the purpose of improving waterfowl survival and reproduction. In order to select optimal land plots, relationship between critical characteristics of habitats and population metrics should be studied and modeled (Smith, 2011). For example, Baveco et al. (2017) combined species distribution and resource depletion models for selecting locations of refuge for pink-footed goose Anser brachyrhynchus in Norway. Species distribution was modeled using Quasi-Poisson generalized mixed model, while resource depletion model was simulated using the mechanistic model.

Alternative method of modeling animal movement is using state-space models (SSM). SSMs combine process (mechanistic model of animal movement) and observation (probability of observing an animal given its state) models. The "state" refers not only to location, but also to other variables, such as the mode (sleeping, foraging), fitness (energy balance, health) and other descriptors. The process model is used to make predictions about the future state from the current state (Markov condition), while observation model links these predictions to the observations (likelihood of seeing these states in the data) using either maximum likelihood methods or Bayesian methods (including MCMC and particle filtering, also known as sequential importance sampling).

Patch selection process is one of the strongest predictors for spatial distribution of animals in the natural landscapes. Clausen et al. (2018) studied wintering choices by pink-footed geese and found high level of plasticity exhibited by migratory waterfowl populations in selecting foraging plots driven by the "explorative" behavior of a few members of the flock.

Marginal Value Theorem (MVT), proposed by Charnov in 1976, predicts when a forager should depart from a given patch in to a new feeding location. Miller et al. (2017) compared various implementation of 
MVT including classical (Charnov's) MVT, online MVT, reinforcement learning-based algorithms, as well as extended MVT methods. These models take travel time to a new plot explicitly into account, weighing it against the energy intake and risk to survival.

Explicit (mechanistic) population models can not only more accurately fit the data, but can also provide more accurate predictions outside of range of conditions which were anticipated during model development (Nichols et al., 1995). For many decades ordinary differential equations (ODEs) were the model of choice for biologists and mathematicians modeling the natural phenomena. But as the computation cost dropped, new class of spatially-explicit simulation models came into prominence both in biology education and research (Bodine et al., 2020).

Agent-based models (ABM), also known as individual-based models, are simulation tools for studying populations (Grimm and Railsback, 2005). Their objective is to study the dynamics emerging from decisions ${ }^{5}$ made by groups of agents, regardless of their cognitive ability (e.g. collective movement of animals in response to available resources or changes in the environment, their decision to settle/leave, forage or interact).

ABMs originated from the work of Craig Raynolds in late 1980s, who studied formation and behavior of bird flocks (Bodine et al., 2020). These models are uniquely positioned to account for individual differences among members of population, including their incomplete knowledge of the surrounding environment, since every agent is simulated independently. ABMs are capable of explicitly accounting for habitat quality independent of species density and incorporating spatial-temporal dynamics of biological systems and their habitats (McLane et al., 2011). They are also well suited for communication, as results from spatially explicit models can be presented using map features (Wickwire et al., 2011). Optimal decisions made by individual agents can have significant consequences for population and the surrounding ecosystem (DeAngelis and Diaz, 2019). Management policies related to conservation should explicitly account for animal behavior and preferences with regards to selection and use of habitats, as well as their response to changes in the external environment.

Spatially-explicit ABMs can combine representation of environments with animal behavior/movement and their ability to learn. Accounting for the spatial aspect of the environments (and agents within them) is crucial for capturing the effects arising from habitat heterogeneity and agent behavior (Wickwire et al., 2011). ABMs can represent environments either explicitly or implicitly and account for animal movement either mechanistically (e.g. random walk) or through explicit modeling of behavior (i.e. animal response to stimuli). The explicit accounting for interaction between agents and their environments is what sets ABMs apart from other modeling approaches.

ABMs represent the status of agents and their environments, and enable predicting possible change of these conditions in the short term (Railsback and Harvey, 2002). Evolutionary dynamics of population can also be modeled using genetic algorithm (Eliassen et al., 2016), possibly in combination with neural network (Morales et al., 2005; Okunishi et al., 2009).

Because ABMs can simulate agents and the environment over multiple timestamps, they can be used to simulate adaptive management programs and evaluate their performance through virtual experimentation (Loomis et al., 2008). Spatially-explicit models can also be used for creating virtual environments for decision making (Bishop et al., 2009). Wickwire et al. (2011) provide a review of spatially explicit exposure models in the ecology literature. Most of the reviewed models (10 out of 14) allow modeling of agent movement. Over half of the models include probabilistic features, which potentially allows for modeling and quantification of uncertainty.

In the past decade, the following specialized ABMs have been developed and applied to waterfowl management problems:

- Pettifor et al. model is a spatially-explicit, year-round, behavior-based model applied to two European populations of geese: barnacle goose Branta leucopsis and the dark-bellied brent goose Branta bernicla (Pettifor et al., 2000).

\footnotetext{
${ }^{5}$ Here a "decision" means a situation, when one of two or more options is selected, regardless of whether the choice is conscious (Ydenberg, 2010)
} 
- AlmaSS model. The purpose of this model is to study how changes to habitat affect movement, reproduction and mortality of animals (Topping et al., 2019). The Animal, Landscape, and Man Simulation System (ALMaSS) model has also been utilized for modeling abundance-occupancy relationship (Høye et al., 2012), and for modeling and supporting ISMPs under AEWA goose management project (Williams et al., 2018). The main modules are implemented in $\mathrm{C}++$ and are open for modification and extension (Topping et al., 2003).

- SWAMP model is an ABM for modeling waterfowl foraging on the wintering grounds in the North America (Miller et al., 2014). The model is implemented in Java using MASON spatially explicit agent library (Luke et al., 2005).

- MORPH model is an open-source fitness-maximization ABM built for the purpose of predicting the effect of environmental changes on foraging animal populations (Stillman, 2008). The model, written in Borland Delphi 7, has been applied to various coastal birds, but can be extended to any forager-pray animal populations.

There is a large number of general-purpose programming environments and libraries for developing ABMs, as well as those built for simulating environments and ecosystems (Abar et al., 2017; Pal et al., 2020) (collectively referred here as "agent-oriented software development environments", ASDEs). Majority of ASDEs are free and open-source, most written in compiled languages, such Java or C++/C\# and ship as extension libraries (for example, RePast or MASON), providing substantial user flexibility in designing and scripting unique ABM tailored to a particular type of agents and environments. Some ASDEs are shipped with custom graphical interface for specifying the model (e.g. HexSim) or a domain-specific scripting language (e.g. NetLogo).

The two dominant data-analysis languages also have specialized packages for designing and developing ABMs: Mesa and SpaDES for Python and R, respectively. Despite the performance limitations posed by the interpreted language, these packages offer data analysts an opportunity to quickly prototype simulation model and analyze results from it without the demands of the software development competence posed by compiled languages.

Recently, Julia-based Agents.jl has emerged, promising to combine the convenience of data manipulation and analysis with the power of scalable computing and simulation offered by type-stable compiled languages (Vahdati, 2019).

\subsubsection{Human dimensions}

Environmental decisions, more often than not, involve humans. Harvest policies affect hunters and farmers, habitat development plans affect landowners and neighboring citizens and even wildlife population monitoring require joint efforts of hunters, birdwatchers and ornithologists in producing the best estimates possible. Therefore any waterfowl management policy needs to be considered in the integrated social-ecological context incorporating stakeholder objectives and incentives (Madsen et al., 2015b, Johnson et al. (2015)). This is achieved by bringing together and integrating data and insight from different disciplines, including biology, environmental psychology, economics, geophysics and ecology, into what is known as the study of coupled human and natural systems (Liu et al., 2007).

Wider involvement of stakeholders is given the top priority in the European Goose Management Platform's recommendations (Stroud et al., 2017). Various stakeholder groups, such as research organizations, national agencies, hunting organizations, local administrations, activist groups and regular citizens, can play an important role in conservation efforts and contribute towards sustainable environmental resource management. In the recent years, citizen science, defined as "non-expert effort to collect and/or process data as part of scientific inquiry", has gotten attention in scientific literature (Aceves-Bueno et al., 2015). When planned and executed properly, it can produce sound scientific results, generate high quality data, contribute to solving environmental problems and help validate hypotheses (McKinley et al., 2017). 
Although it is quite clear that geese foraging in agricultural landscapes cause conflict with farming, the local residents' perception of the situation may be quite different (Fox, 2019). The study of the public attitudes to Giant Canada Geese in central Missouri found that the urban residents tend to look favorably upon geese, and generally oppose lethal management alternatives, unless it is obvious that the damage caused by waterfowl is demonstrably high and there are no real alternatives to lethal control measures (Coluccy et al., 2001).

Modeling people's behavior can also be challenging due to imperfect reasoning and partial knowledge possessed by human actors. For example, (Simonsen et al., 2017) did not find that Mid-Norway farmers' use of scaring to reduce crop damage on their land plots corresponded to the actual use of the same land plots by foraging geese. Some of those farmers who needed to protect their fields did not do so, because they thought scaring is difficult and ineffective. Likewise, owners of those land plots which did not require an intervention, engaged in geese scaring out of the misconceptions regarding the effectiveness of occasional scaring or just to signal their frustration and dissatisfaction with the support provided by the authorities (Eythórsson et al., 2017).

Decision making in conservation can sometimes be affected by changes in the management objectives, especially when multiple groups of human agents are involved. Mid-Norway's compensation scheme was first established with an objective of accommodating migrant pink-footed and barnacle geese during the spring staging and reducing the conflict between geese and agriculture. Under the scheme the farmers would receive the payment for agreeing to offer some of their land as a goose refuge. In order to improve the match between the subsidized areas and actual staging of geese, spatially explicit model was developed and adopted for distribution of subsidies in 2009-2013 (Baveco et al., 2017). The model predicted which pastures were likely to be preferred by geese, taking into account the suitability of landscape. The farmers, however, perceived the subsidy to be the compensation for actual loss caused by geese and expressed dissatisfaction with how the subsidy was distributed. In 2015, in an attempt to increase legitimacy of the subsidy distribution, local authorities agreed to shift the compensation basis from predicted loss (as predicted by model) to actually assessed loss (as reported by farmers and verified by agricultural authorities).

This shifted the scheme objective from securing the geese refuge areas to a post-hoc compensation to farmers, which relies heavily on continuous monitoring and dispute resolution (Eythórsson et al., 2017). Assessing crop damage from grazing geese in the spring staging locations is a notoriously difficult task. Even under the experimental setting (with proper control and randomization setup) only the effects of the heaviest grazing are detectable and statistically significant, and even then the results vary from site to site and require species distribution modeling (Bjerke et al., 2014).

These and other challenges involving complex interactions between human and natural systems require integrated interdisciplinary approach and coupled agent-based modeling (Liu et al., 2007). Unlike traditional ecological or social research, which excludes the human and ecological effects, respectively, the new approach to studying these interconnected ecosystems must integrate the tools and techniques found in each of the disciplines and direct them at capturing the effects emerging from their interaction.

Modeling human systems require multi-agent approach, where each group of stakeholders sharing similar value function is modeled separately. For example, Monticino et al. (2007) in their model or land-use, created separate agent classes from municipal governments, land developers and homeowners, each with a complex set of values and objectives. Similarly, Malawska and Topping (2016) used ABM to model land-use decision making of plot owners, accounting for the differences in goals of classic producers and environmentallyoriented farmers. Taking it one step further, Williams et al. (2018) took the same AlmaSS-based model and added hunter agents, seeking the best locations for harvesting geese. The authors used pattern-oriented modeling (POM) with minimum number of decision rules, developed iteratively, validating the model against real-world data patterns at every iteration. Hunters play critical role in successful implementation of adaptive harvest management, as many international species management plans rely on the recreations hunters to curtail otherwise exponentially expanding populations of waterfowl species (Williams et al., 2019). 


\section{Conclusion}

Environmental decision making is rich with uncertainties, which need to be properly acknowledged and accounted for in the formal decision making process. In this article we introduced the topic of decision making under risk and uncertainty, reviewed the foundations of uncertainty analysis and decision analysis and showed how they fit into the various decision processes followed by many modern environmental projects. In particular, we focused on Multi-Criteria Decision Analysis (MCDA) and Adaptive Management, as iterative form of decision analysis process.

International waterfowl management projects in the USA and in Europe adopted the Adaptive Management framework to designing harvest and habitat regulations. This approach is based on the Structured Decision Making, which represents the formal decision analysis process based on the MCDA work of Raiffa and Keeney(Keeney and Raiffa, 1976). This framework has been widely applied and adopted in international waterfowl management projects in the US and in Europe.

Engineering approach to decision analysis places a system model in the center of attention for the project team to discuss and contribute to. The article introduces different population models used in waterfowl management and the types of uncertainties they are addressing. Finally the Markov Decision Process as a method for modeling recurring decision making in stochastic environments is introduced. The article discusses learning in Adaptive Management, the differences between "passive" and "active" approach to adaptive management and introduces the concept of Value of Information, as a measure of learning value.

The history of waterfowl management represents a success story, demonstrating how science can contribute to sound decision making in conservation and environmental domains. First in the USA and later in Europe, politicians and policy makers turned to scientists for advice and guidance in designing the sustainable hunting and conservation policies, based on scientific evidence, continuous monitoring and wide stakeholder engagement. The article reviews the human-nature conflict, the stakeholders involved and the various objectives they represent. We, then, briefly review the common management responses (alternatives) typically proposed in waterfowl management problems and the knowledge gaps described in scientific literature on this topic.

Finally the three areas of waterfowl management are presented and discussed. Our focus was primarily on the models used for modeling of harvest, habitats and waterfowl interaction with humans. Adaptive Harvest Management projects in the USA and in Europe actively utilize multi-model inference under various mortality and fertility hypotheses. Partial observability is accounted for in POMDP models, which are solved with stochastic dynamic programming. AEWA-organized projects focusing on individual management plans for several goose species introduce population targets which serve as thresholds for management actions. Given that today in Europe geese hunting is primarily done in Denmark and Norway, the project's ability to affect the age composition of the hunting bag is limited.

Decisions related to habitats are primarily informed by with state-space models and ABMs. Several specialized agent-based models have been developed and utilized for waterfowl management problems and new applications of simulated models are actively developed.

Human dimension in waterfowl research requires combination of ABM and MCDA, explicitly accounting for differences in agent objectives and incomplete knowledge. The difficult dilemmas and challenges posed by human-nature conflict can be elucidated by coupled social-biological models and decision frameworks, which integrate human decision making and environmental system response. 


\section{Appendix A}

\section{Markov Decision Process}

Let's consider a system which changes over discrete periods of time $\left\{t_{0}, t_{0}+1, \ldots, T\right\}$ (both because of stochastic nature of environmental conditions, but also in response to management actions). The state of the system at time $t$ can be registered with $x_{t}$ which results in a set of system realizations $\$\left\{\mathrm{x}_{-}\left\{\mathrm{t} \_0\right\}\right.$, $\left.\mathrm{x} \_\left\{\mathrm{t} \_0+1\right\}, \ldots, \mathrm{x} \_\mathrm{T}\right\}$. Management actions undertaken in a specific time period can then be denoted with $A_{t}$. Modeled systems can therefore be differentiated as known (system parameters $\beta$ are known) or not fully known (parametric/model uncertainty is present) and observable or partially observable. Natural systems are rarely fully observable, but sometimes they are assumed as such, based on the assumption that the recurring surveys characterize the system perfectly (Williams et al., 2002).

\section{Known and observable process}

Known and observable system is assumed to have a Markovian transition property:

$$
x_{t+1}=F\left(x_{t}, a_{t}, z_{t}\right)
$$

where $a_{t} \in A_{t}$ is an action undertaken in time $t$, and $z_{t}$ represents unexplained variation in the system. Because parameters of the system $\beta$ are known, Markovian transition probabilities $P\left(x_{t+1} \mid x_{t}, a_{t}\right)$ are suppressed. The reward for the management actions in this system varies with the state of the system $R\left(a_{t} \mid x_{t}\right)$ over time $t$. Value function, then accumulates these returns over time for a particular policy $A_{t}$ starting in system state $x_{t}$.

$$
V\left(A_{t} \mid x_{t}\right)=E\left[\sum_{\tau=t}^{T} R\left(a_{\tau} \mid x_{\tau}\right) \mid x_{t}\right]
$$

or if a single-step return is by itself stochastic, it can be replaced by expected value with respect to return probability:

$$
V\left(A_{t} \mid x_{t}\right)=E\left[\sum_{\tau=t}^{T} E\left[R\left(a_{\tau} \mid x_{\tau}\right)\right] \mid x_{t}\right]
$$

\section{Uncertain but observable process}

For observable systems with uncertainty, transition probabilities are parametrized by uncertain parameter $\beta$ and are given by:

$$
x_{t+1}=F_{\beta}\left(x_{t}, a_{t}, z_{t}\right)
$$

with $a_{t} \in A_{t}$ being action undertaken in time $t$, and $z_{t}$ represents variability in the system, which induces Markovian property $P_{\beta}\left(x_{t+1} \mid x_{t}, a_{t}\right)$, which when averaged over time produces:

$$
\bar{P}\left(x_{t+1} \mid x_{t}, a_{t}, q_{t}\right)=\int_{\beta} q_{t}(\beta) P_{\beta}\left(x_{t+1} \mid x_{t}, a_{t}\right) d \beta
$$

Parameter $\beta$ is distributed over time as $q_{t}(\beta)$ (parameter state). Parameter state also evolves over time and can be expressed in terms of previous parameter state and the system state at time $t+1$, as $q_{t+1}=$ $Q\left(q_{t}, a_{t}, x_{t+1}\right)$. The transition from $q_{t}$ to $q_{t+1}$ can then be expressed via Bayes theorem: 


$$
q_{t+1}(\beta)=\frac{q_{t}(\beta) P_{\beta}\left(x_{t+1} \mid x_{t}, a_{t}\right)}{\bar{P}\left(x_{t+1} \mid x_{t}, a_{t}, q_{t}\right)}
$$

The reward function is also parameter-specific with action- and state-specific returns parametrized by $\beta$ accumulated over time produces:

$$
V_{\beta}\left(A_{t} \mid x_{t}\right)=E\left[\sum_{\tau=t}^{T} E\left[R_{\beta}\left(a_{\tau} \mid x_{\tau}\right)\right] \mid x_{t}\right]
$$

And when averaged over the space of parameter values:

$$
V\left(A_{t} \mid x_{t}, q_{t}\right)=\int_{\beta} q_{t}(\beta) V_{\beta}\left(A_{t} \mid x_{t}\right) d \beta
$$

Therefore reward function should account for both system state and parameter state at any given point in time. In this case learning is represented by changes in he parameter state $q_{t}$ resulting from management actions $A_{t}$ (Williams et al., 2002).

\section{Known but partially observable process}

Partially observable process adds a significant amount of complexity to modeling. It is, however, most common situation in natural system, where system state is not always possible to monitor.

A main feature of partial observability is that the system state $x_{t}$ is expressed only through probability. We need to introduce two new terms. First of them is stochastic model of observability $y_{t}=G\left(x_{t}, \varepsilon_{t}\right)$, which specifies observation at time $t$ as a stochastic function of a (latent) system state $x_{t}$ with random noise element $\varepsilon_{t}$. This means that the observational state $y_{t}$ is only stochastically linked to the actual state $x_{t}$ via a function $f\left(y_{t} \mid x_{t}\right)$.

In the situation, actual (unobserved) state of the system should be represented by a distribution of possible values, commonly referred as a "belief state" $p_{t}$. The belief state evolves over time, as data from observations accumulate:

$$
p_{t+1}=H\left(p_{t}, a_{t}, y_{t+1}\right)
$$

Here the assumption is that $p_{t}$ is a sufficient statistic for both initial belief and history, so that conditioning on older values of $p$ provides no additional information about $p_{t+1}$ (Markov property). Here the evolution of belief over time can also be expressed with Bayes theorem:

$$
p_{t+1}\left(x_{t+1}\right)=\frac{f\left(y_{t+1} \mid x_{t+1}\right) \sum_{x_{t}} P\left(x_{t+1} \mid x_{t}, a_{t}\right) p_{t}\left(x_{t}\right)}{\bar{P}\left(y_{t+1} \mid p_{t}, a_{t}\right)}
$$

where $\bar{P}\left(y_{t+1} \mid p_{t}, a_{t}\right)$ is averaged probability of observing $y_{t+1}$ at time $t+1$ :

$$
\bar{P}\left(y_{t+1} \mid p_{t}, a_{t}\right)=\sum_{x_{t+1}} f\left(y_{t+1} \mid x_{t+1}\right) \sum_{x_{t}} P\left(x_{t+1} \mid x_{t}, a_{t}\right) p_{t}\left(x_{t}\right)
$$

Markovian transition probability for belief states $p_{t}$ is then given by $\operatorname{Pr}\left(p_{t+1} \mid p_{t}, a_{t}\right)$, which can be described by an indicator function

$$
I_{\{p\}}\left(y \mid p_{t}, a_{t}\right)= \begin{cases}1 & \text { if } H\left(p_{t}, a_{t}, y\right)=p \\ 0 & \text { otherwise }\end{cases}
$$


The function takes a non-zero value only if random variable $y$ produces a transition of $p_{t}$ to $p$. Then probability of such transition from $p_{t}$ to $p_{t+1}$ is

$$
\operatorname{Pr}\left(p_{t+1} \mid p_{t}, a_{t}\right)=\sum_{y_{t+1}} I_{\left\{p_{t+1}\right\}}\left(y_{t+1} \mid p_{t}, a_{t}\right) \bar{P}\left(y_{t+1} \mid p_{t}, a_{t}\right)
$$

The reward structure is then averaging $R\left(a_{t} \mid x_{t}\right)$ over the belief states at times $t$ to become

$$
\bar{R}\left(a_{t}, p_{t}\right)=\sum_{x_{t}} R\left(a_{t} \mid x_{t}\right)
$$

Accumulated rewards over policy $A_{t}$, which starts with belief $p_{t}$ at time $t$ :

$$
V\left(A_{t} \mid p_{t}\right)=E\left[\sum_{\tau=t}^{T} \bar{R}\left(a_{\tau} \mid p_{\tau}\right) \mid p_{t}\right]
$$

Therefore partial observability requires specification of $f\left(y_{t} \mid x_{t}\right), p_{t}\left(x_{t}\right)$ and $\operatorname{Pr}\left(p_{t+1} \mid p_{t}, a_{t}\right)$. In order to simplify this complexity practitioners often make estimates of system states and specify them directly, as if these estimates describe the system state perfectly.

\section{Uncertain partially observable process}

As in the model above we are working with stochastic observation model $y_{t}=G\left(x_{t}, \varepsilon_{t}\right)$, linking observation $y_{t}$ to a latent state $x_{t}$ with conditional probability $f\left(y_{t} \mid x_{t}\right)$.

State transitions are now dependent on unknown parameter $\beta$ and given by $x_{t+1}=F_{\beta}\left(x_{t}, a_{t}, z_{t}\right)$ with management control at time $t$ given by $a_{t}$ and random element $z_{t}$. Parametrized Markovian transition probability structure is then $P_{\beta}\left(x_{t+1} \mid x_{t}, a_{t}\right)$.

The state of knowledge about the parameter $\beta$ is traced by $q_{t}$ distributed as $q_{t}(\beta)$ for each value of $\beta$ at time $t$. Belief about the system state $x_{t}$ is denoted with $p_{t}$, distributed as $p_{t}\left(x_{t}\right)$ for each value of $x_{t}$ at time $t$. Averaging of transition probabilities over values of belief states results in:

$$
\bar{P}_{\beta}\left(y_{t+1} \mid p_{t}, a_{t}\right)=\sum_{x_{t+1}} f\left(y_{t+1} \mid x_{x+1}\right) \sum_{x_{t}} P_{\beta}\left(x_{t+1} \mid x_{t}, a_{t}\right) p\left(x_{t}\right)
$$

which when subsequently averaged over the state of parameters produces probability of observing $y_{t+1}$ at the time $t+1$.

$$
\overline{\bar{P}}\left(y_{t+1} \mid p_{t}, a_{t}, q_{t}\right)=\int_{\beta} \bar{P}_{\beta}\left(y_{t+1} \mid p_{t}, a_{t}\right) q_{t}(\beta) d \beta
$$

Both state of beliefs and state of parameters evolve over time. The belief state evolves as:

$$
p_{t+1}=H\left(p_{t}, a_{t}, y_{t+1}, q_{t}\right)=\int_{\beta} H\left(p_{t}, a_{t}, y_{t+1}, \beta\right) q_{t}(\beta) d \beta
$$

where transition from belief state $p_{t}$ to a new state $p_{t+1}$ can be expressed using Bayes theorem as:

$$
p_{t+1}\left(t_{t+1}\right)=\frac{f\left(y_{t+1} \mid x_{t+1}\right) \sum_{x_{t}} \bar{P}\left(x_{t+1} \mid x_{t}, a_{t}, q_{t}\right) p_{t}\left(x_{t}\right)}{\overline{\bar{P}}\left(y_{t+1} \mid p_{t}, a_{t}, q_{t}\right)}
$$


where

$$
\bar{P}\left(x_{t+1} \mid x_{t}, a_{t}, q_{t}\right)=\int_{\beta} q_{t}(\beta) P_{\beta}\left(x_{t+1} \mid x_{t}, a_{t}\right) d \beta
$$

Similarly to the previous cases, probability of transition from $p_{t}$ to $p_{t+1}, \operatorname{Pr}\left(p_{t+1} \mid p_{t}, a_{t}, \beta\right)$ can be described as an indicator function

$$
I_{\{p\}}\left(y \mid p_{t}, a_{t}, \beta\right)= \begin{cases}1 & \text { if } H\left(p_{t}, a_{t}, y, \beta\right)=p \\ 0 & \text { otherwise }\end{cases}
$$

which takes non-zero value only if a random variable $y$ in $H\left(p_{t}, a_{t}, y, \beta\right)$ results in transition from $p_{t}$ to $p_{t+1}$. Therefore the transition probability becomes

$$
\operatorname{Pr}\left(p_{t+1} \mid p_{t}, a_{t}, \beta\right)=\sum_{y_{t+1}} I_{\left\{p_{t+1}\right\}}\left(y_{t+1} \mid p_{t}, a_{t}, \beta\right) \bar{P}_{\beta}\left(y_{t+1} \mid p_{t}, a_{t}\right)
$$

or when averaged over the parameter states

$$
\overline{\operatorname{Pr}}\left(p_{t+1} \mid p_{t}, a_{t}, q_{t}\right)=\int_{\text {beta }} \operatorname{Pr}\left(p_{t+1} \mid p_{t}, a_{t}, \beta\right) q_{t}(\beta) d \beta
$$

The parameter state also evolves through time as $q_{t+1}=Q\left(q_{t}, a_{t}, y_{t+1}, p_{t}\right)$ with transition (expressed using Bayes theorem):

$$
q_{t+1}(\beta)=\frac{q_{t}(\beta) \operatorname{Pr}\left(p_{t+1} p_{t}, a_{t}, \beta\right)}{\overline{\operatorname{Pr}}\left(p_{t+1} \mid p_{t}, a_{t}, q_{t}\right)}
$$

The parametrized reward $R_{\beta}\left(a_{t}, x_{t}\right)$ can be averaged over system states as:

$$
\bar{R}_{\beta}\left(a_{t} \mid p_{t}\right)=\sum_{x_{t}} p_{t}\left(x_{t}\right) R_{\beta}\left(a_{t} \mid x_{t}\right)
$$

with returns accumulated over time represented as:

$$
V_{\beta}\left(A_{t} \mid p_{t}\right)=E\left[\sum_{\tau=t}^{T} \bar{R}_{\beta}\left(a_{\tau} \mid p_{\tau}\right) \mid p_{t}\right]
$$

The accumulated returns can be then averaged over the parameter space, producing the value function:

$$
V\left(A_{t} \mid p_{t}, q_{t}\right)=\int_{\beta} q_{t}(\beta) V_{\beta}\left(A_{t} \mid p_{t}\right) d \beta
$$

\section{Appendix B}

\section{"Additive" vs "Compensatory" mortality hypotheses}

Common balance equation for breeding population size as a function of annual survival and reproduction rates proposed by Johnson et al. (2002) (expanded in Johnson et al. (2015)) for North American mallards can be expressed as: 


$$
N_{t+1}=N_{t}\left\{m S_{t, A M}+(1-m)\left[S_{t, A F}+R_{t}\left(S_{t, J F}+S_{t, J M} \varphi_{F}^{\text {sum }} / \varphi_{M}^{\text {sum }}\right)\right]\right\}
$$

where

$t$ - year

$N_{t}$ - breeding population size in year $t$

$m$ - proportion of males in the breeding population

$S_{A M}, S_{A F}, S_{J F}, S_{J M}$ - annual survival rates for adult males, adult females, juvenile females and juvenile males, respectively

$R_{t}$ reproductive rate (autumn age ratio of females) in year $t$

$\varphi_{F}^{\text {sum }} / \varphi_{M}^{\text {sum }}$ - ratio of female $(F)$ to male $(M)$ summer survival. This ratio accounts for different anniversaries for the population survey (May) and the vital rate survey (Aug).

In practice, however, because breeding-ground surveys systematically underestimate the survival and reproduction rates[], bias-correcting factors need to be introduced for $N_{t}$ and $R_{t}$ to adjust the survival and reproduction estimates, respectively.

For survival variables we can adopt a very general model, which relates hunting mortality to total annual survival (indices for age, sex and location have been omitted for simplicity):

$$
E\left(S_{t}\right)=S_{0}\left(1-\beta K_{t}\right)
$$

where

$S_{t}$ - probability that the bird alive at the beginning of the hunting season in year $t$ is also alive at the same time the following year $(t+1)$

$S_{0}$ - probability that the bird alive at the beginning of the hunting season in year $t$ is also alive at the same time the following year $(t+1)$ in the absence of hunting mortality

$K_{t}$ - probability that the bird alive at the beginning of the hunting season in year $t$ would die from hunting causes by the same time the following year $(t+1)$, assuming absence of any non-hunting mortality

$\beta$ - slope parameter relating $S_{t}$ and $K_{t}$

$E$ expected value

When parameter $\beta$ is 1 , the equation corresponds to the additive mortality hypothesis. Under $\beta$ equal to zero, compensatory mortality hypothesis can be postulated.

For alternative formulation of the survival hypotheses we are referring to Johnson et al. (1997) and Conn and Kendall (2004) 


\section{References}

Abar, S., Theodoropoulos, G. K., Lemarinier, P., and O'Hare, G. M. (2017). Agent Based Modelling and Simulation tools: A review of the state-of-art software. Computer Science Review, 24:13-33.

Aceves-Bueno, E., Adeleye, A. S., Bradley, D., Tyler Brandt, W., Callery, P., Feraud, M., Garner, K. L., Gentry, R., Huang, Y., McCullough, I., Pearlman, I., Sutherland, S. A., Wilkinson, W., Yang, Y., Zink, T., Anderson, S. E., and Tague, C. (2015). Citizen Science as an Approach for Overcoming Insufficient Monitoring and Inadequate Stakeholder Buy-in in Adaptive Management: Criteria and Evidence. Ecosystems, 18(3):493-506.

Addison, P. F. E., Rumpff, L., Bau, S. S., Carey, J. M., Chee, Y. E., Jarrad, F. C., McBride, M. F., and Burgman, M. A. (2013). Practical solutions for making models indispensable in conservation decisionmaking. Diversity and Distributions, 19(5-6):490-502.

AEWA (2020). Parties and Range States. AEWA. https://www.unep-aewa.org/en/parties-range-states.

Allen, C. R., Fontaine, J. J., Pope, K. L., and Garmestani, A. S. (2011). Adaptive management for a turbulent future. Journal of Environmental Management, 92(5):1339-1345.

Allen, C. R. and Gunderson, L. H. (2011). Pathology and failure in the design and implementation of adaptive management. Journal of Environmental Management, 92(5):1379-1384.

Arrow, K. J. (1957). Decision Theory and Operations Research. Operations Research, 5(6):765-774.

Bainbridge, I. (2017). Goose management in Scotland: An overview. Ambio, 46(S2):224-230.

Baker, R. E., Peña, J.-M., Jayamohan, J., and Jérusalem, A. (2018). Mechanistic models versus machine learning, a fight worth fighting for the biological community? Biology Letters, 14(5).

Barnard, S. and Elliott, M. (2015). The 10-tenets of adaptive management and sustainability: An holistic framework for understanding and managing the socio-ecological system. Environmental Science \& Policy, $51: 181-191$.

Bauer, S., Lisovski, S., Eikelenboom-Kil, R. J. F. M., Shariati, M., and Nolet, B. A. (2018). Shooting may aggravate rather than alleviate conflicts between migratory geese and agriculture. Journal of Applied Ecology, 55(6):2653-2662.

Baveco, J. M., Bergjord, A.-K., Bjerke, J. W., Chudzińska, M. E., Pellissier, L., Simonsen, C. E., Madsen, J., Tombre, I. M., and Nolet, B. A. (2017). Combining modelling tools to evaluate a goose management scheme. Ambio, 46(S2):210-223.

Bibby, C. J., editor (2000). Bird Census Techniques. Academic, London; San Diego, 2nd ed edition.

Bishop, I. D., Stock, C., and Williams, K. J. (2009). Using virtual environments and agent models in multi-criteria decision-making. Land Use Policy, 26(1):87-94.

Bjerke, J. W., Bergjord, A. K., Tombre, I. M., and Madsen, J. (2014). Reduced dairy grassland yields in Central Norway after a single springtime grazing event by pink-footed geese. Grass and Forage Science, 69(1):129-139.

Bjerkén, A. (2020). Agree without Aggregating. An Extension of Multi-Criteria Decision Theory for Multiple Decision Makers. Master Thesis, University of Akureyri.

Bodine, E. N., Panoff, R. M., Voit, E. O., and Weisstein, A. E. (2020). Agent-Based Modeling and Simulation in Mathematics and Biology Education. Bulletin of Mathematical Biology, 82(8):101.

Bojke, L., Claxton, K., Sculpher, M., and Palmer, S. (2009). Characterizing Structural Uncertainty in Decision Analytic Models: A Review and Application of Methods. Value in Health, 12(5):739-749. 
Bradbeer, D. R., Rosenquist, C., Christensen, T. K., and Fox, A. D. (2017). Crowded skies: Conflicts between expanding goose populations and aviation safety. Ambio, 46(S2):290-300.

Brown, R. V. (1989). Toward a prescriptive science and technology of decision aiding. Annals of Operations Research, 19(1):465-483.

Burnham, K. P. (1993). A theory for the combined analysis of ring recovery and recapture data. In Lebreton, J. D. and North, P. M., editors, Marked Individuals in the Study of Bird Populations, pages 199-213. Birkhäuser Verlag, Basel.

Caswell, H. (2001). Matrix Population Models: Construction, Analysis, and Interpretation. Sinauer Associates, Sunderland, Mass, 2nd ed edition.

Chades, I., Tarnopolskaya, T., Dunstall, S., Rhodes, J., and Tulloch, A. (2015). A comparison of adaptive management and real options approaches for environmental decisions under uncertainty. In MODSIM2015, 21st International Congress on Modelling and Simulation. Modelling and Simulation Society of Australia and New Zealand. The Modelling and Simulation Society of Australia and New Zealand Inc.

Clausen, K., Balsby, T., Goma, V., and Madsen, J. (2019). Using re-sighting data to estimate population size of Pink-footed Geese (Anser brachyrhynchus). Ornis Fennica.

Clausen, K. K., Christensen, T. K., Gundersen, O. M., and Madsen, J. (2017). Impact of hunting along the migration corridor of pink-footed geese Anser brachyrhynchus - implications for sustainable harvest management. Journal of Applied Ecology, 54(5):1563-1570.

Clausen, K. K., Madsen, J., Cottaar, F., Kuijken, E., and Verscheure, C. (2018). Highly dynamic wintering strategies in migratory geese: Coping with environmental change. Global Change Biology, 24(7):3214-3225.

Coluccy, J. M., Drobney, R. D., Graber, D. A., Sheriff, S. L., and Witter, D. J. (2001). Attitudes of Central Missouri Residents toward Local Giant Canada Geese and Management Alternatives. Wildlife Society Bulletin (1973-2006), 29(1):116-123.

Conn, P. B. and Kendall, W. L. (2004). Evaluating Mallard Adaptive Management Models with Time Series. The Journal of Wildlife Management, 68(4):1065-1081.

Conroy, M. J., Runge, M. C., Nichols, J. D., Stodola, K. W., and Cooper, R. J. (2011). Conservation in the face of climate change: The roles of alternative models, monitoring, and adaptation in confronting and reducing uncertainty. Biological Conservation, 144(4):1204-1213.

Cooch, E. G., Guillemain, M., Boomer, G. S., Lebreton, J.-D., and Nichols, J. D. (2014). The effects of harvest on waterfowl populations. Wildfowl, 0(0):220-276.

Cox, L. A. T. (2012). Confronting Deep Uncertainties in Risk Analysis. Risk Analysis, 32(10):1607-1629.

DeAngelis, D. L. and Diaz, S. G. (2019). Decision-Making in Agent-Based Modeling: A Current Review and Future Prospectus. Frontiers in Ecology and Evolution, 6.

Decker, D. J. and Chase, L. C. (1997). Human Dimensions of Living with Wildlife: A Management Challenge for the 21st Century. Wildlife Society Bulletin (1973-2006), 25(4):788-795.

Derbyshire, J. (2019). Answers to questions on uncertainty in geography: Old lessons and new scenario tools. Environment and Planning A: Economy and Space, page 0308518X1987788.

Duncan, D. H. and Wintle, B. A. (2008). Towards Adaptive Management of Native Vegetation in Regional Landscapes. In Pettit, C., Cartwright, W., Bishop, I., Lowell, K., Pullar, D., and Duncan, D., editors, Landscape Analysis and Visualisation, pages 159-182. Springer Berlin Heidelberg, Berlin, Heidelberg.

Dupont, R. R., Baxter, T. E., and Theodore, L. (1998). Environmental Management: Problems and Solutions. Lewis Publishers. 
Eliassen, S., Andersen, B. S., Jørgensen, C., and Giske, J. (2016). From sensing to emergent adaptations: Modelling the proximate architecture for decision-making. Ecological Modelling, 326:90-100.

Elmberg, J. (2003). Density-dependent breeding success in mallards Anas platyrhynchos on a eutrophic lake. Wildlife Biology, 9(4):67-73.

Elmberg, J., Nummi, P., Pöysä, H., Sjöberg, K., Gunnarsson, G., Clausen, P., Guillemain, M., Rodrigues, D., and Väänänen, V.-M. (2006). The scientific basis for new and sustainable management of migratory European ducks. Wildlife Biology, 12(2):121-127.

European Parliament and Council of the European Union (2010). Directive 2009/147/EC on the conservation of wild birds. Official Journal of the European Union, (020):7-25.

Everitt, B. S. and Skrondal, A. (2010). The Cambridge Dictionary of Statistics: Fourth Edition. Cambridge University Press, Cambridge.

Eythórsson, E., Tombre, I. M., and Madsen, J. (2017). Goose management schemes to resolve conflicts with agriculture: Theory, practice and effects. Ambio, 46(S2):231-240.

Feldman, D. L. (2008). Barriers to Adaptive Management: Lessons from the Apalachicola-ChattahoocheeFlint Compact. Society \& Natural Resources, 21(6):512-525.

Fischer, G. and Otswald, J. (2001). Knowledge management: Problems, promises, realities, and challenges. IEEE Intelligent Systems, 16(1):60-72.

Fox, A. D. (2019). Urban Geese - looking to North America for experiences to guide management in Europe? Wildfowl, 69(69):3-27-27.

Fox, A. D. and Abraham, K. F. (2017). Why geese benefit from the transition from natural vegetation to agriculture. Ambio, 46(S2):188-197.

Fox, A. D., Elmberg, J., Tombre, I. M., and Hessel, R. (2017). Agriculture and herbivorous waterfowl: A review of the scientific basis for improved management. Biological Reviews, 92(2):854-877.

Fox, A. D. and Madsen, J. (2017). Threatened species to super-abundance: The unexpected international implications of successful goose conservation. Ambio, 46(2):179-187.

Fox, C. R. and Ülkümen, G. (2011). Distinguishing two dimensions of uncertainty. Perspectives on thinking, judging, and decision making, pages 21-35.

Ganter, B. and Madsen, J. (2001). An examination of methods to estimate population size in wintering geese. Bird Study, 48(1):90-101.

Gelman, A., Simpson, D., and Betancourt, M. (2017). The prior can generally only be understood in the context of the likelihood. Entropy, 19(10):555.

Gillson, L., Biggs, H., Smit, I. P. J., Virah-Sawmy, M., and Rogers, K. (2019). Finding Common Ground between Adaptive Management and Evidence-Based Approaches to Biodiversity Conservation. Trends in Ecology \& Evolution, 34(1):31-44.

Goodwin, P. and Wright, G. (2014). Decision Analysis for Management Judgment. Wiley, Hoboken, New Jersey, 5th edition edition.

Grant, E. H. C., Muths, E., Katz, R. A., Canessa, S., Adams, M. J., Ballard, J. R., Berger, L., Briggs, C. J., Coleman, J. T., Gray, M. J., Harris, M. C., Harris, R. N., Hossack, B., Huyvaert, K. P., Kolby, J., Lips, K. R., Lovich, R. E., McCallum, H. I., Mendelson, J. R., Nanjappa, P., Olson, D. H., Powers, J. G., Richgels, K. L., Russell, R. E., Schmidt, B. R., der Sluijs, A. S.-v., Watry, M. K., Woodhams, D. C., and White, C. L. (2017). Using decision analysis to support proactive management of emerging infectious wildlife diseases. Frontiers in Ecology and the Environment, 15(4):214-221. 
Gregory, R., editor (2012). Structured Decision Making: A Practical Guide to Environmental Management Choices. Wiley-Blackwell, Chichester, West Sussex ; Hoboken, N.J.

Gregory, R. and Long, G. (2009). Using Structured Decision Making to Help Implement a Precautionary Approach to Endangered Species Management. Risk Analysis, 29(4):518-532.

Gregory, R., McDaniels, T., and Fields, D. (2001). Decision Aiding, Not Dispute Resolution: Creating Insights through Structured Environmental Decisions. Journal of Policy Analysis and Management, 20(3):415-432.

Gregory, R., Ohlson, D., and Arvai, J. (2006). Deconstructing adaptive management: Criteria for applications to environmental management. Ecological Applications, 16(6):2411-2425.

Grimm, V. and Railsback, S. F. (2005). Individual-Based Modeling and Ecology, volume 8. Princeton university press.

Gunderson, L. and Light, S. S. (2007). Adaptive management and adaptive governance in the everglades ecosystem. Policy Sciences, 39(4):323-334.

Gunderson, L. H., Light, S. S., Holling, C. S., and Recorded Books, I. (2010). Barriers And Bridges To The Renewal Of Regional Ecosystems. Columbia University Press, New York.

Gunnarsson, G., Elmberg, J., Pöysä, H., Nummi, P., Sjöberg, K., Dessborn, L., and Arzel, C. (2013). Density dependence in ducks: A review of the evidence. European Journal of Wildlife Research, 59(3):305-321.

Hanley, N. (1992). Are there environmental limits to cost benefit analysis? Environmental and Resource Economics, 2(1):33-59.

Holling, C. S. and Programme, U. N. E., editors (1978). Adaptive Environmental Assessment and Management. Number 3 in International Series on Applied Systems Analysis. International Institute for Applied Systems Analysis ; Wiley, [Laxenburg, Austria] : Chichester ; New York.

Holopainen, S., Arzel, C., Elmberg, J., Fox, A. D., Guillemain, M., Gunnarsson, G., Nummi, P., Sjöberg, K., Väänänen, V.-M., Alhainen, M., and Pöysä, H. (2018). Sustainable management of migratory European ducks: Finding model species. Wildlife Biology, 2018(1).

Howard, R. A. (1980). An Assessment of Decision Analysis. Operations Research, 28(1):4-27.

Howard, R. A. (2007). The Foundations of Decision Analysis Revisited. In von Winterfeldt, D., Miles Jr., R. F., and Edwards, W., editors, Advances in Decision Analysis: From Foundations to Applications, pages 32-56. Cambridge University Press, Cambridge.

Howard, R. A., Matheson, J. E., and Miller, K. L. (1977). Readings in Decision Analysis. Decision Analysis Group, Stanford Research Institute.

Høye, T. T., Skov, F., and Topping, C. J. (2012). Interpreting outputs of agent-based models using abundance-occupancy relationships. Ecological Indicators, 20:221-227.

Huang, I. B., Keisler, J., and Linkov, I. (2011). Multi-criteria decision analysis in environmental sciences: Ten years of applications and trends. Science of The Total Environment, 409(19):3578-3594.

Jaynes, E. T. (2003). Probability Theory: The Logic of Science. Cambridge University Press, first edition.

Johnson, B. (1999). Introduction to the Special Feature: Adaptive Management - Scientifically Sound, Socially Challenged? Conservation Ecology, 3(1).

Johnson, F. and Case, D. (2000). Adaptive Regulation of Waterfowl Harvests: Lessons Learned and Prospects for the Future. US Fish $\&$ Wildife Publications.

Johnson, F. and Williams, K. (1999). Protocol and Practice in the Adaptive Management of Waterfowl Harvests. Conservation Ecology, 3(1). 
Johnson, F. A. (2011). Learning and adaptation in the management of waterfowl harvests. Journal of Environmental Management, 92(5):1385-1394.

Johnson, F. A., Alhainen, M., Fox, A. D., Madsen, J., and Guillemain, M. (2018). Making do with less: Must sparse data preclude informed harvest strategies for European waterbirds? Ecological Applications, 28(2):427-441.

Johnson, F. A., Boomer, G. S., Williams, B. K., Nichols, J. D., and Case, D. J. (2015). Multilevel Learning in the Adaptive Management of Waterfowl Harvests: 20 Years and Counting. Wildlife Society Bulletin, 39(1):9-19.

Johnson, F. A., Dubovsky, J. A., Runge, M. C., and Eggeman, D. R. (2002). A revised protocol for the adaptive harvest management of eastern mallards. Fish and Wildlife Service, US Dept. Interior, Washington, DC 13pp.[online] URL: http://migratorybirds. fws. gov/reports/ahm02/emal-ahm-2002. pdf.

Johnson, F. A., Jensen, G. H., Madsen, J., and Williams, B. K. (2014). Uncertainty, robustness, and the value of information in managing an expanding Arctic goose population. Ecological Modelling, 273:186-199.

Johnson, F. A., Moore, C. T., Kendall, W. L., Dubovsky, J. A., Caithamer, D. F., Kelley, J. R., and Williams, B. K. (1997). Uncertainty and the Management of Mallard Harvests. The Journal of Wildlife Management, 61(1):202-216.

Johnson, F. A., Walters, M. A. H., and Boomer, G. S. (2012). Allowable levels of take for the trade in Nearctic songbirds. Ecological Applications, 22(4):1114-1130.

Johnson, F. A., Williams, B., Nichols, J., Hines, J. E., Kendall, W., Smith, G., and Caithamer, D. (1993). Developing an adaptive management strategy for harvesting waterfowl in North America. In Transactions of the... North American Wildlife and Natural Resources Conference (USA).

Johnson, F. A., Zimmerman, G. S., Huang, M. T., Padding, P. I., Balkcom, G. D., Runge, M. C., and Devers, P. K. (2019). Multi-species duck harvesting using dynamic programming and multi-criteria decision analysis. Journal of Applied Ecology, 56(6):1447-1459.

Kear, J. and Hulme, M. (2005). Ducks, Geese and Swans. Vol. 1, General Chapters. Special Accounts (Anhima to Salvadorina). Oxford University Press.

Keeney, R., Hammond, J., and Raiffa, H. (1999). Smart choices: A guide to making better decisions.

Keeney, R. L. and Raiffa, H. (1976). Decisions with Multiple Objectives: Preferences and Value Tradeoffs. Wiley Series in Probability and Mathematical Statistics. Wiley, New York.

Keith, D. A., Martin, T. G., McDonald-Madden, E., and Walters, C. (2011). Uncertainty and adaptive management for biodiversity conservation. Biological Conservation, 144(4):1175-1178.

Kleindorfer, P. R. (2010). Reflections on decision making under uncertainty. The Known, the Unknown, and the Unknowable in Financial Risk Management: Measurement and Theory Advancing Practice, pages 164-193.

Knight, F. H. (1921). Risk, Uncertainty and Profit, volume 31. Houghton Mifflin.

Koffijberg, K., Schekkerman, H., van der Jeugd, H., Hornman, M., and van Winden, E. (2017). Responses of wintering geese to the designation of goose foraging areas in The Netherlands. Ambio, 46(S2):241-250.

Koneff, M. D., Zimmerman, G. S., Dwyer, C. P., Fleming, K. K., Padding, P. I., Devers, P. K., Johnson, F. A., Runge, M. C., and Roberts, A. J. (2017). Evaluation of harvest and information needs for North American sea ducks. PLOS ONE, 12(4):e0175411.

Lahoz-Monfort, J. J., Guillera-Arroita, G., and Hauser, C. E. (2014). From planning to implementation: Explaining connections between adaptive management and population models. Frontiers in Ecology and Evolution, 2. 
Lee, K. N. (1999). Appraising adaptive management. Conservation Ecology, 3(2).

Lefebvre, J., Gauthier, G., Giroux, J.-F., Reed, A., Reed, E. T., and Bélanger, L. (2017). The greater snow goose Anser caerulescens atlanticus: Managing an overabundant population. Ambio, 46(S2):262-274.

Lindström, Å., Enemar, A., Andersson, G., von Proschwitz, T., and Nyholm, N. E. I. (2005). Densitydependent reproductive output in relation to a drastically varying food supply: Getting the density measure right. Oikos, 110(1):155-163.

Linkov, I., Satterstrom, F. K., Kiker, G., Batchelor, C., Bridges, T., and Ferguson, E. (2006). From comparative risk assessment to multi-criteria decision analysis and adaptive management: Recent developments and applications. Environment International, 32(8):1072-1093.

Liu, J., Dietz, T., Carpenter, S. R., Alberti, M., Folke, C., Moran, E., Pell, A. N., Deadman, P., Kratz, T., Lubchenco, J., Ostrom, E., Ouyang, Z., Provencher, W., Redman, C. L., Schneider, S. H., and Taylor, W. W. (2007). Complexity of Coupled Human and Natural Systems. Science, 317(5844):1513-1516.

Loomis, J., Bond, C., and Harpman, D. (2008). The Potential of Agent-Based Modelling for Performing Economic Analysis of Adaptive Natural Resource Management. Journal of Natural Resources Policy Research, 1(1):35-48.

Luke, S., Cioffi-Revilla, C., Panait, L., Sullivan, K., and Balan, G. (2005). MASON: A Multiagent Simulation Environment. SIMULATION, 81(7):517-527.

Lyons, J. E., Runge, M. C., Laskowski, H. P., and Kendall, W. L. (2008). Monitoring in the Context of Structured Decision-Making and Adaptive Management. The Journal of Wildlife Management, 72(8):1683-1692.

Madsen, J., Bunnefeld, N., Nagy, S., Griffin, C., du Rau, P. D., Mondain-Monval, J.-Y., Hearn, R., Grauer, A., Merkel, F. R., Williams, J. H., et al. (2015a). Guidelines on sustainable harvest of migratory waterbirds. AEWA conservation guidelines no. 5 .

Madsen, J., Guillemain, M., Nagy, S., du Rau, P. D., Mondain-Monval, J.-Y., Griffin, C., Williams, J. H., Bunnefeld, N., Czajkowski, A., Hearn, R., et al. (2015b). Towards sustainable management of huntable migratory waterbirds in Europe: A report by the Waterbird Harvest Specialist Group of Wetlands International.

Madsen, J., Williams, J., Barov, B., Bergholtz, T., Brodde, M., Ceulemans, T., Clausen, P., Cottaar, F., Espelien, A., Middleton, A., Nagy, S., Roggeman, S., Simonsen, N., Smolders, S., Størkersen, Ø., Sørensen, H., and Verscheure, C. (2012). AEWA International Species Management Plan for the Svalbard Population of the Pink-footed goose Anser brachyrhynchus.

Madsen, J., Williams, J. H., Johnson, F. A., Tombre, I. M., Dereliev, S., and Kuijken, E. (2017). Implementation of the first adaptive management plan for a European migratory waterbird population: The case of the Svalbard pink-footed goose Anser brachyrhynchus. Ambio, 46(2):275-289.

Malawska, A. and Topping, C. J. (2016). Evaluating the role of behavioral factors and practical constraints in the performance of an agent-based model of farmer decision making. Agricultural Systems, 143:136-146.

Marescot, L., Chapron, G., Chadès, I., Fackler, P. L., Duchamp, C., Marboutin, E., and Gimenez, O. (2013). Complex decisions made simple: A primer on stochastic dynamic programming. Methods in Ecology and Evolution, 4(9):872-884.

Martin, J., Runge, M. C., Nichols, J. D., Lubow, B. C., and Kendall, W. L. (2009). Structured decision making as a conceptual framework to identify thresholds for conservation and management. Ecological Applications, 19(5):1079-1090.

Matheson, J. E. (2005). Decision Analysis = Decision Engineering. In Emerging Theory, Methods, and Applications, INFORMS TutORials in Operations Research, chapter 7, pages 195-212. INFORMS. 
McFadden, J. E., Hiller, T. L., and Tyre, A. J. (2011). Evaluating the efficacy of adaptive management approaches: Is there a formula for success? Journal of Environmental Management, 92(5):1354-1359.

McKinley, D. C., Miller-Rushing, A. J., Ballard, H. L., Bonney, R., Brown, H., Cook-Patton, S. C., Evans, D. M., French, R. A., Parrish, J. K., Phillips, T. B., Ryan, S. F., Shanley, L. A., Shirk, J. L., Stepenuck, K. F., Weltzin, J. F., Wiggins, A., Boyle, O. D., Briggs, R. D., Chapin, S. F., Hewitt, D. A., Preuss, P. W., and Soukup, M. A. (2017). Citizen science can improve conservation science, natural resource management, and environmental protection. Biological Conservation, 208:15-28.

McLain, R. J. and Lee, R. G. (1996). Adaptive management: Promises and pitfalls. Environmental Management, 20(4):437-448.

McLane, A. J., Semeniuk, C., McDermid, G. J., and Marceau, D. J. (2011). The role of agent-based models in wildlife ecology and management. Ecological Modelling, 222(8):1544-1556.

McLoughlin, C. A. and Thoms, M. C. (2015). Integrative learning for practicing adaptive resource management. Ecology and Society, 20(1).

Memarzadeh, M. and Boettiger, C. (2018). Adaptive management of ecological systems under partial observability. Biological Conservation, 224:9-15.

Miller, M. L., Ringelman, K. M., Eadie, J. M., and Schank, J. C. (2017). Time to fly: A comparison of marginal value theorem approximations in an agent-based model of foraging waterfowl. Ecological Modelling, 351:77-86.

Miller, M. L., Ringelman, K. M., Schank, J. C., and Eadie, J. M. (2014). SWAMP: An agent-based model for wetland and waterfowl conservation management. SIMULATION, 90(1):52-68.

Monticino, M., Acevedo, M., Callicott, B., Cogdill, T., and Lindquist, C. (2007). Coupled human and natural systems: A multi-agent-based approach. Environmental Modelling \& Software, 22(5):656-663.

Moore, A. L., Walker, L., Runge, M. C., McDonald-Madden, E., and McCarthy, M. A. (2017). Two-step adaptive management for choosing between two management actions. Ecological Applications, 27(4):12101222 .

Moore, J. L. and Runge, M. C. (2012). Combining Structured Decision Making and Value-of-Information Analyses to Identify Robust Management Strategies. Conservation Biology, 26(5):810-820.

Morales, J. M., Fortin, D., Frair, J. L., and Merrill, E. H. (2005). Adaptive models for large herbivore movements in heterogeneous landscapes. Landscape Ecology, 20(3):301-316.

Morgan, M. G., Henrion, M., and Small, M. (1990). Uncertainty: A Guide to Dealing with Uncertainty in Quantitative Risk and Policy Analysis. Cambridge university press.

Nichols, J. D. (1991). Responses of North American duck populations to exploitation. In C.M. Perrins, J.-D. Lebreton, G.J.M. Hirons, and Oxford University Press, editors, Bird Population Studies: Relevance to Conservation and Management, pages 498-525. Oxford University Press, New York.

Nichols, J. D., Johnson, F. A., and Williams, B. K. (1995). Managing North American Waterfowl in the Face of Uncertainty. Annual Review of Ecology and Systematics, 26:177-199.

Nichols, J. D. and Williams, B. K. (2006). Monitoring for conservation. Trends in ecology 63 evolution, 21(12):668-673.

Niel, C. and Lebreton, J.-D. (2005). Using Demographic Invariants to Detect Overharvested Bird Populations from Incomplete Data. Conservation Biology, 19(3):826-835.

Nilsson, L. and Hermansson, C. (2019). The establishment of a new major moulting site for Greylag Geese Anser anser at Lake Hornborgasjön, southern Sweden. Wildfowl, 69(69):93-104-104.

O'Hagan, T. (2004). Dicing with the unknown. Significance, 1(3):132-133. 
Okunishi, T., Yamanaka, Y., and Ito, S.-i. (2009). A simulation model for Japanese sardine (Sardinops melanostictus) migrations in the western North Pacific. Ecological Modelling, 220(4):462-479.

Owen, M. (1990). The damage-conservation interface illustrated by geese. Ibis, 132(2):238-252.

Pahl-Wostl, C. (2009). A conceptual framework for analysing adaptive capacity and multi-level learning processes in resource governance regimes. Global Environmental Change, 19(3):354-365.

Pal, C.-V., Leon, F., Paprzycki, M., and Ganzha, M. (2020). A Review of Platforms for the Development of Agent Systems. arXiv:200\%.08961 [cs].

Parnell, G. S., Bresnick, T. A., Tani, S. N., and Johnson, E. R. (2013). Handbook of Decision Analysis: Parnell/Handbook of Decision Analysis. John Wiley \& Sons, Inc., Hoboken, NJ, USA.

Pettifor, R. A., Caldow, R. W. G., Rowcliffe, J. M., Goss-Custard, J. D., Black, J. M., Hodder, K. H., Houston, A. I., Lang, A., and Webb, J. (2000). Spatially explicit, individual-based, behavioural models of the annual cycle of two migratory goose populations. Journal of Applied Ecology, 37(s1):103-135.

Possingham, H., Andelman, S., Noon, B., Trombulak, S., and Pulliam, H. (2001). Making smart conservation decisions. Conservation biology: research priorities for the next decade, 23:225-244.

Pöysä, H. (2004). Ecological basis of sustainable harvesting: Is the prevailing paradigm of compensatory mortality still valid? Oikos, 104(3):612-615.

Pöysä, H., Dessborn, L., Elmberg, J., Gunnarsson, G., Nummi, P., Sjöberg, K., Suhonen, S., and Söderquist, P. (2013). Harvest mortality in North American mallards: A reply to Sedinger and Herzog. The Journal of Wildlife Management, 77(4):653-654.

Pozzi, M., Memarzadeh, M., and Klima, K. (2017). Hidden-Model Processes for Adaptive Management under Uncertain Climate Change. Journal of Infrastructure Systems, 23(4):04017022.

Puterman, M. L., editor (1994). Markov Decision Processes. Wiley Series in Probability and Statistics. John Wiley \& Sons, Inc., Hoboken, NJ, USA.

Raha, S. (2010). Achieving Clarity on Value. PhD thesis, Stanford University.

Raiffa, H. (1970). Decision Analysis: Introductory Lectures on Choices under Uncertainty. Behavioral Science Quantitative Methods. Addison-Wesley, Reading, Mass., 2. print edition.

Railsback, S. F. and Harvey, B. C. (2002). Analysis of Habitat-Selection Rules Using Anindividual-Based Model. Ecology, 83(7):1817-1830.

Rehme, S. E., Powell, L. A., and Allen, C. R. (2011). Multimodel inference and adaptive management. Journal of Environmental Management, 92(5):1360-1364.

Rhodes, L. and Dawson, R. (2013). Lessons Learned from Lessons Learned: Lessons Learned from Lessons Learned. Knowledge and Process Management, 20(3):154-160.

Ricker, W. E. (1954). Stock and Recruitment. Journal of the Fisheries Research Board of Canada, 11(5):559623.

Rist, L., Campbell, B. M., and Frost, P. (2013a). Adaptive management: Where are we now? Environmental Conservation, 40(1):5-18.

Rist, L., Felton, A., Samuelsson, L., Sandström, C., and Rosvall, O. (2013b). A new paradigm for adaptive management. Ecology \&3 society, 18(4):63.

Roberts, A., Eadie, J. M., Howerter, D. W., Johnson, F. A., Nichols, J. D., Runge, M. C., Vrtiska, M. P., and Williams, B. K. (2018). Strengthening links between waterfowl research and management. The Journal of Wildlife Management, 82(2):260-265. 
Runge, M. C. (2011). An Introduction to Adaptive Management for Threatened and Endangered Species. Journal of Fish and Wildlife Management, 2(2):220-233.

Runge, M. C., Converse, S. J., and Lyons, J. E. (2011). Which uncertainty? Using expert elicitation and expected value of information to design an adaptive program. Biological Conservation, 144(4):1214-1223.

Runge, M. C., Sauer, J. R., Avery, M. L., Blackwell, B. F., and Koneff, M. D. (2009). Assessing Allowable Take of Migratory Birds. Journal of Wildlife Management, 73(4):556-565.

Savage, L. J. (1972). The Foundations of Statistics. Courier Corporation.

Schreiber, E. S. G., Bearlin, A. R., Nicol, S. J., and Todd, C. R. (2004). Adaptive management: A synthesis of current understanding and effective application. Ecological Management $\mathcal{E}$ Restoration, 5(3):177-182.

Schuwirth, N., Borgwardt, F., Domisch, S., Friedrichs, M., Kattwinkel, M., Kneis, D., Kuemmerlen, M., Langhans, S. D., Martínez-López, J., and Vermeiren, P. (2019). How to make ecological models useful for environmental management. Ecological Modelling, 411:108784.

Sheaffer, S. E. and Jarvis, R. L. (1995). Bias in Canada Goose Population Size Estimates from Sighting Data. The Journal of Wildlife Management, 59(3):464-473.

Simonsen, C. E., Madsen, J., Tombre, I. M., and Nabe-Nielsen, J. (2016). Is it worthwhile scaring geese to alleviate damage to crops? - An experimental study. Journal of Applied Ecology, 53(3):916-924.

Simonsen, C. E., Tombre, I. M., and Madsen, J. (2017). Scaring as a tool to alleviate crop damage by geese: Revealing differences between farmers' perceptions and the scale of the problem. Ambio, 46(2):319-327.

Smith, C. B. (2011). Adaptive management on the central Platte River - Science, engineering, and decision analysis to assist in the recovery of four species. Journal of Environmental Management, 92(5):1414-1419.

Smith, D. R., McGowan, C. P., Daily, J. P., Nichols, J. D., Sweka, J. A., and Lyons, J. E. (2013). Evaluating a multispecies adaptive management framework: Must uncertainty impede effective decision-making? Journal of Applied Ecology, 50(6):1431-1440.

Stillman, R. A. (2008). MORPH-An individual-based model to predict the effect of environmental change on foraging animal populations. Ecological Modelling, 216(3):265-276.

Stroud, D. A., Madsen, J., and Fox, A. D. (2017). Key actions towards the sustainable management of European geese. Ambio, 46(S2):328-338.

Sutherland, W. J., Pullin, A. S., Dolman, P. M., and Knight, T. M. (2004). The need for evidence-based conservation. Trends in Ecology \& Evolution, 19(6):305-308.

Topping, C. J., Dalby, L., and Valdez, J. W. (2019). Landscape-scale simulations as a tool in multi-criteria decision making for agri-environment schemes. bioRxiv, page 524181.

Topping, C. J., Hansen, T. S., Jensen, T. S., Jepsen, J. U., Nikolajsen, F., and Odderskær, P. (2003). ALMaSS, an agent-based model for animals in temperate European landscapes. Ecological Modelling, 167(1-2):65-82.

Tulloch, A. I. T., Nicol, S., and Bunnefeld, N. (2017). Quantifying the expected value of uncertain management choices for over-abundant Greylag Geese. Biological Conservation, 214:147-155.

Vahdati, A. (2019). Agents.jl: Agent-based modeling framework in Julia. Journal of Open Source Software, $4(42): 1611$.

van der Jeugd, H. P. and Kwak, A. (2017). Management of a Dutch resident barnacle goose Branta leucopsis population: How can results from counts, ringing and hunting bag statistics be reconciled? Ambio, $46(\mathrm{~S} 2): 251-261$. 
Walters, C. (1997). Challenges in adaptive management of riparian and coastal ecosystems. Ecology and Society, 1(2):art1.

Walters, C. J. (2007). Is Adaptive Management Helping to Solve Fisheries Problems? AMBIO: A Journal of the Human Environment, 36(4):304-307.

Walters, C. J. and Hilborn, R. (1978). Ecological Optimization and Adaptive Management. Annual Review of Ecology and Systematics, 9(1):157-188.

Warner, J. F., Wesselink, A. J., and Geldof, G. D. (2018). The politics of adaptive climate management: Scientific recipes and lived reality. WIREs Climate Change, 9(3):e515.

Wickwire, T., Johnson, M. S., Hope, B. K., and Greenberg, M. S. (2011). Spatially explicit ecological exposure models: A rationale for and path toward their increased acceptance and use. Integrated Environmental Assessment and Management, 7(2):158-168.

Williams, B. K. (1997). Approaches to the Management of Waterfowl under Uncertainty. Wildlife Society Bulletin (1973-2006), 25(3):714-720.

Williams, B. K. (2009). Markov decision processes in natural resources management: Observability and uncertainty. Ecological Modelling, 220(6):830-840.

Williams, B. K. (2011a). Adaptive management of natural resources - framework and issues. Journal of Environmental Management, 92(5):1346-1353.

Williams, B. K. (2011b). Passive and active adaptive management: Approaches and an example. Journal of Environmental Management, 92(5):1371-1378.

Williams, B. K. and Brown, E. D. (2014). Adaptive Management: From More Talk to Real Action. Environmental Management, 53(2):465-479.

Williams, B. K. and Brown, E. D. (2016). Technical challenges in the application of adaptive management. Biological Conservation, 195:255-263.

Williams, B. K. and Brown, E. D. (2018). Double-Loop Learning in Adaptive Management: The Need, the Challenge, and the Opportunity. Environmental Management, 62(6):995-1006.

Williams, B. K. and Johnson, F. A. (2015). Value of information in natural resource management: Technical developments and application to pink-footed geese. Ecology and Evolution, 5(2):466-474.

Williams, B. K. and Johnson, F. A. (2017). Frequencies of decision making and monitoring in adaptive resource management. PLOS ONE, 12(8):e0182934.

Williams, B. K. and Johnson, F. A. (2018). Value of sample information in dynamic, structurally uncertain resource systems. PLOS ONE, 13(6):e0199326.

Williams, B. K., Johnson, F. A., and Wilkins, K. (1996). Uncertainty and the Adaptive Management of Waterfowl Harvests. The Journal of Wildlife Management, 60(2):223-232.

Williams, B. K., Nichols, J. D., and Conroy, M. J. (2002). Analysis and Management of Animal Populations: Modeling, Estimation, and Decision Making. Academic Press, San Diego.

Williams, B. K., Szaro, R. C., and Shapiro, C. D. (2009). Adaptive management: The US Department of the Interior technical guide. Technical report, US Department of the Interior.

Williams, J. H. (2018). Human Uncertainties in Adaptive Management: Recognizing and Dealing with a Neglected Constituent. PhD thesis, Aarhus Universitet.

Williams, J. H., Balsby, T. J. S., Ørsted Nielsen, H., Asferg, T., and Madsen, J. (2019). Managing geese with recreational hunters? Ambio, 48(3):217-229. 
Williams, J. H. and Madsen, J. (2013). Stakeholder Perspectives and Values when Setting Waterbird Population Targets: Implications for Flyway Management Planning in a European Context. PLoS ONE, 8(11):e81836.

Williams, J. H., Topping, C. J., Dalby, L., Clausen, K. K., and Madsen, J. (2018). Where to go goose hunting? Using pattern-oriented modeling to better understand human decision processes. Human Dimensions of Wildlife, 23(6):533-551.

Ydenberg, R. (2010). Decision theory. In Westneat, D. F. and Fox, C. W., editors, Evolutionary Behavioral Ecology (DF Westneat and CW Fox, Eds.)., pages 131-147. Oxford University Press. 